\title{
Diferentes propuestas para el despliegue de la Economía Social y Solidaria: ecosistemas, sistemas, mercados sociales, circuitos solidarios y redes solidarias
}

\author{
Different proposals for the development of the Social and Solidarity \\ Economy: Ecosystems, Systems, Social Markets, Solidarity Circuits \\ and Solidarity Networks
}

\author{
Asier Arcos-Alonso*1, Amaia Garcia-Azpuru² \\ ${ }^{1}$ Profesor adjunto. Universidad del País Vasco (UPV/EHU) \\ 2 Profesora adjunta. Universidad del País Vasco (UPV/EHU)
}

\begin{abstract}
Resumen: Este artículo presenta una revisión de diferentes propuestas desarrolladas desde el marco de Economía Social y Solidaria como alternativas de carácter integral al modelo de desarrollo capitalista imperante.

Diversos organismos, redes y la propia academia estructuran propuestas identificadas de manera diferente -redes, circuitos, mercados sociales, sistemas o ecosistemas - con las que ofrecen marcos de actuación que ayuden a delimitar, implantar y desplegar conjuntos articulados de entidades que operen con objetivos trascendentes al bienestar de sus propios componentes y que apunten al bienestar común.

Se aborda la revisión de las diferentes propuestas a través de un estudio comparativo del que se extraen las principales variables comunes a todas ellas, así como la intensidad en la implantación de las mismas. Sin embargo, existen limitaciones y quedan retos a la hora de llevar a cabo los diversos objetivos de despliegue que se plantean, como son el mantener los principios y valores comunes de ESS durante el proceso, hacer frente de manera innovadora a las dificultades de crecimiento estratégico, organizacional y de concertación de las propuestas o incorporar explícitamente a las estrategias de escalamiento la dimensión de los cuidados.
\end{abstract}

Palabras clave: Economía Social y Solidaria, Ecosistemas, Sistemas Económicos, Despliegue.

\begin{abstract}
This article presents a review of the different proposals developed within the framework of the Social and Solidarity Economy as comprehensive alternatives to the current capitalist development model.

Various organisations, networks and academia itself have structured proposals such as - networks, circuits, social markets, systems or ecosystems with which they offer frameworks for action that help to delimit, implement and deploy articulated sets of entities that operate with objectives transcendent to the well-being of their own members and that of society itself.

The review of the different proposals is approached through a comparative study from which the main variables common to all of them are extracted, as well the intensity of their implementation.

However, there are limitations and challenges in achieving the various deployment objectives proposed, such as maintaining common SSE principles and values throughout the process, dealing innovatively with the difficulties of strategic, organisational and concerted growth of the proposals, and explicitly incorporating the care dimension into the scaling-up strategies.
\end{abstract}

\section{Keywords:}

Códigos Econlit: A130, P00, P49

\footnotetext{
* Correspondencia a/Corresponding author: Asier Arcos-Alonso. University of the Basque Country UPV/EHU. Calle Comandante Izarduy, 23 (Vitoria-Gasteiz. Spain) - asier.arcos@ehu.eus - https://orcid.org/0000-0001-8737-5531

Cómo citar/How to cite: Arcos-Alonso, Asier; Garcia-Azpuru, Amaia (2021). "Diferentes propuestas para el despliegue de la Economía Social y Solidaria: ecosistemas, sistemas, mercados sociales, circuitos solidarios y redes solidarias», GIZAEKOA Revista Vasca de Economía Social, 18, 191-233. (https://doi.org/10.1387/gizaekoa.22880).
}

Recibido: 31/05/2021; aceptado: 14/06/2021

ISSN 1698-7446 - eISSN 2444-3107 / (C) 2021 UPV/EHU 


\section{Introducción}

En este artículo se presenta una revisión de siete propuestas desarrolladas desde el marco de la Economía Social y Solidaria (ESS) como alternativas de carácter integral al modelo de desarrollo capitalista imperante.

Propuestas que vienen del mundo de la sociología, las economías alternativas y los movimientos sociales, y cuyo nexo es considerar como propuesta socioeconómica, la alternativa dada por la ESS. Todas ellas tienen un carácter ecosistémico, dado que proponen marcos de cambio y transformación integrales, aunque en algunas no se utilice este término en su denominación (Arcos-Alonso, 2021). Su origen, en varios casos, es la respuesta que desde los movimientos sociales y las economías populares y solidarias han dado a las falencias que origina el sistema capitalista.

Así, entre ellas, se encuentran los Ecosistemas Innovadores de Economía Social y Solidaria según la Organización Internacional de Trabajo (OIT), que ponen énfasis en la financiación de las entidades y sus repercusiones a nivel de empleo. Así mismo, aparecen las Empresas Sociales y sus Ecosistemas, cuyo análisis se realiza en base a las características explicitadas por la red EMES a través de un mapeo de entidades que las cumplen en Europa. También en el ámbito vasco se proponen los Sistemas Locales de Economía Social y Solidaria (SLESS), que relacionan las características de las redes propias del contexto territorial y sus particularidades con las del territorio, vinculándolas a las redes y, la innovación, la inclusión o el desarrollo local.

Otra propuesta analizada es la de las Redes Solidarias originarias del ámbito productivo (Moran-Esparza, 2008) y basadas en mercados solidarios y de comercio justo (Melo-Lisboa, 2004). Estas redes generan conexiones y sinergias colectivas, que fortalecen el tejido en el territorio (Mance, 2002). Su interacción se realiza a través de los flujos económicos, culturales y naturales (Mance, 2008). Por su parte, la propuesta denominada los Circuitos Económicos Solidarios (Lopera y Mora, 2009) e interculturales (Jiménez, 2016) tienen como punto central la incorporación de los movimientos sociales, el desarrollo de formas comunitarias basadas en la reciprocidad y distribución, que alientan el desarrollo territorial, manteniendo sus flujos basados en valores y principios de la ESS (Arcos-Alonso y Morandeira, 2020).

Los Mercados Sociales constituyen otro tipo de propuesta que promueve relaciones de justicia socio ambiental como respuesta a las inequidades generadas por el mercado capitalista. Para ello, articulan redes de producción, distribución y consumo de bienes y servicios basadas en principios éticos, democráticos, ecológicos y solidarios, donde se integren organizaciones de la economía solidaria y consumidores (Crespo y Sabin, 2014). Por 
último, se recogen las claves para construir un Sistema Económico Social y Solidario (SEES) (Coraggio, 2015, 2016), como elementos necesarios para desarrollar un programa de acción estratégica para la transición, basado en prácticas económicas articuladas a nivel micro, meso, macro y sistémico, junto con dimensiones sociales, culturales y políticas.

Se ha desarrollado una revisión de la literatura científica de las diferentes alternativas ecosistémicas al sistema capitalista. El análisis es descriptivo, recogiendo la información de fuentes secundarias, como artículos de investigación, memorias e informes. De la misma revisión se han extraído veintitrés variables comunes a todas las propuestas para poder realizar un estudio comparativo. Así, se contrastan las posiciones de las propuestas ecosistémicas en función de la intensidad que representan para ellas dichas variables en su desarrollo y despliegue.

\section{La Economía Social y Solidaria como marco}

En la actualidad, la sociedad es muy desigual y las oportunidades no son las mismas para todas las personas. Las desigualdades sociales y económicas se han agravado, afectando al sistema de generación de bienes y servicios, de producción y consumo, con el consiguiente deterioro del planeta, y la sostenibilidad de una vida digna. En este contexto la Economía Social y Solidaria (ESS), cuyo origen es la Economía Social, plantea un modelo económico diferente, basado en valores sociales y reivindica el carácter solidario y comunitario y la función social de la economía. El término ESS es cada vez más utilizado tanto en ámbitos locales ${ }^{1}$ (REAS, Red de Redes de Economía Alternativa y Solidaria y REAS Euskadi²), como internacionales (Red Intercontinental de Promoción de la ESS, el Instituto de Investigación de las Naciones Unidas para el Desarrollo Social —UNRISD—).

La ESS entiende que todo proceso económico (producción, distribución, consumo y financiación) ha de ser justo, equitativo, recíproco, basado en la ayuda mutua, donde las personas están en el centro (Pérez de Mendiguren, Etxezarreta y Guridi, 2009). Mantiene un carácter heterogéneo, de modo que se entiende como un conjunto muy diverso de teorías,

${ }^{1}$ La red Olatukoop, una de las dos referentes en el País Vasco utiliza el término «Ekonomia Sozial Eraldatzailea» o «Economía Social Transformadora», tratando de marcar las diferencias con la Economía Social y en especial con el cooperativismo tradicional.

2 REAS Euskadi forma parte de REAS Red de Redes (https://www.reasred.org/), asociación confederada conformada por 19 ( 15 redes territoriales y 4 redes sectoriales) redes del Estado espańol, y que agrupan en torno a 800 entidades y empresas en el estado en diversos sectores de actividad (REAS, 2021). 
realidades socioeconómicas e institucionales y prácticas tanto empresariales como asociativas.

En la ESS se dan procesos de reciprocidad entre personas y colectivos para un hacer económico de carácter solidario, vinculando así los intereses tanto individuales como colectivos (Moulaert y Ailenei, 2005).

El carácter solidario será su fundamento básico, así como su capacidad de generar beneficios para el desarrollo de la sociedad de tipo social y cultural, además de económicos (Razeto, 1993). En definitiva, lo que se busca, fundamentalmente, es el logro del bienestar de la persona y su entorno, desde una óptica humanista (Askunze, 2013).

La ESS es, por tanto, una práctica transformadora, que pone la actividad económica al servicio de las personas, y no del capital. Ello implica un enfoque económico diferente a los tradicionales.

Ahora bien, como se ha afirmado anteriormente, hay diversidad de planteamientos, aunque a la hora de concretar una definición, hay un acuerdo en el mundo académico de la existencia de dos corrientes mayoritarias a la hora de conceptualizar y definir la ESS: la latinoamericana y la europea (Guerra, 2004; Pérez de Mendiguren et al., 2009).

La primera, la latinoamericana, representada por Razeto, Da Ros, Guerra, Coraggio, Arruda o Singer, defiende un modelo económico dirigido a mejorar la calidad de vida de las personas, y no a que unos pocos acumulen la mayor parte del capital. Plantean que es una alternativa válida al modelo capitalista imperante.

Sin embargo, los diferentes autores ponen la fuerza de la ESS en distintos puntos. Razeto (1999), incide en el camino de la acción transformadora de los movimientos sociales en el marco de la ESS. Por su parte Coraggio (2007a, 2007b), enfatiza el valor de unas relaciones de poder más democráticas, que implican aumentar los niveles de diálogo y cooperación, de decisión colectiva, de reconocimiento de las necesidades y de diseńo de estrategias para su gestión colectiva. Para Singer (2002) la economía solidaria es una estrategia posible de lucha contra las desigualdades sociales y el desempleo, cambiando las relaciones de poder y trabajo actuales.

En cuanto a la segunda corriente, la europea, la progresiva institucionalización de las entidades de la Economía Social tradicional ${ }^{3}$, dio origen a diversas corrientes de renovación o de separación como la Economía Solidaria o la ESS. Defourny, Favreau y Laville (1997) acuñaron el término «Nueva Economía Social», que incluye una amplia gama de realidades y se materializa en redes socioeconómicas en las dimensiones mercantil y no

${ }^{3}$ La definición de la Economía Social se basa en la aproximación científico-académica de CIRIEC-Internacional, aceptada por el Consejo Económico y Social Europeo (CESE). Ver: https://www.eesc.europa.eu/sites/default/files/files/qe-04-17-875-es-n.pdf 
mercantil, añadiendo objetivos sociales y económicos. El término va cambiando a "Economía Solidaria», produciéndose así una confluencia terminológica con los planteamientos latinoamericanos (Pérez de Mendiguren et al., 2009). Se entiende el acto económico con más carga política, social y transformadora, planteando la hibridación de las actividades económicas con principios como la redistribución y la reciprocidad.

Ahora bien, la conceptualización de la economía solidaria en Europa, a su vez, ha adoptado dos enfoques, uno macro y otro micro. El primero, entendido como clave de superación del paradigma actual. Propugna la ruptura con la división entre economía, sociedad y política para democratizarla, y a su vez incluye una dimensión sociopolítica y socioeconómica.

El enfoque micro ${ }^{4}$, desde una perspectiva empresarial, se centra en la praxis de las propias entidades que componen el conjunto de actores de la Economía Solidaria. Se analizan sus características, la forma de funcionamiento y sus formas jurídicas, los sectores donde trabaja, así como sus formas de gestión (Pérez de Mendiguren et al., 2009). Este enfoque permite una mejor comprensión de la realidad de estas iniciativas, resaltando, así mismo, su fuerte vinculación con el territorio y el entorno local. Además, las entidades de ESS tienen una fuerte propensión al trabajo colaborativo y en red, ya que, en muchas ocasiones, es una respuesta a su minúsculo tamaño en relación con el mercado.

En síntesis, tanto a nivel teórico como de realidad práctica la ESS cada vez está cobrando más fuerza, lo que la convierte en una alternativa valiosa a los modelos capitalistas y neoliberales. En el marco de la ESS existen alternativas socialmente innovadoras ante demandas no satisfechas por el Estado, ni por el sector privado, con lo que tiene un componente intrínseco de innovación social notable que requiere un entorno local bien articulado (Arcos-Alonso y Morandeira, 2020).

\section{Propuestas de Ecosistemas desde la Economía Social y Solidaria}

En este apartado se recogen las propuestas teóricas existentes que asentadas en la práctica de las entidades de ESS abogan por un trabajo articulado en red y de carácter ecosistémico. En efecto, la ESS es mucho mayor que la suma de las unidades económicas que componen esta sección de la economía. Cualquier análisis que lo reduzca a sus partes componentes sería insuficiente para abordar elementos clave y transmitir satisfactoriamente la complejidad de la ESS. Para comenzar a comprender los entornos comple-

${ }^{4}$ Pérez de Mendiguren et al. (2009) vinculan este enfoque micro al cuerpo de la literatura sobre la Empresa Social o Social Enterprise. 
jos en los que existen estas organizaciones, cada vez es más habitual la utilización de metáforas como los "ecosistemas" (Barco-Serrano, Bodini, Roy y Salvatori, 2019, p. 8). Sin embargo, tal y como se explica a continuación, aparecen bajo diferentes nomenclaturas, propuestas convergentes en su enfoque integral y propositivo en cuanto al cambio del sistema económico y la búsqueda del bienestar común.

\subsection{Ecosistemas Innovadores de Economía Social y Solidaria según la Organización Internacional de Trabajo - OIT-}

A finales de 2019 salió a la luz una propuesta que trata de clarificar el Ecosistema Innovador de Economía Social y Solidaria por parte de la Organización Internacional del Trabajo (OIT). Propuesta de la que sale un informe denominado «Mecanismos financieros para ESS innovadores de Economía Social y Solidaria» (Barco-Serrano et al., 2019). Dicho informe reconoce el auge de la literatura científica sobre la ESS, muchas particularidades y definiciones, y determina una utilización amplia del término a fin de abarcar la mayoría de sensibilidades con enfoque pragmático del concepto (Barco-Serrano et al., 2019):

La ESS es un concepto general que designa a empresas y organizaciones, en particular cooperativas, sociedades de beneficio mutuo, asociaciones, fundaciones, empresas sin fines de lucro y sociales, que tienen la caracteristica especifica de producir bienes, servicios y conocimiento mientras persiguen objetivos tanto económicos como sociales y fomentan la solidaridad. Todas estas organizaciones también deben compartir las estructuras de gobierno y propiedad que priorizan las necesidades de las partes interesadas que son diferentes de los inversores o accionistas. (p. 7)

El informe alude a que el término "ecosistema» proveniente del ámbito natural, utilizado metafóricamente desde los ańos noventa por la literatura empresarial, cada vez suscita mayor interés académico para ayudar a definir y comprender la manera en que un conjunto de entidades de ESS pueden lograr desarrollarse e interactuar en un entorno delimitado. Aduce, además, que está llamando la atención más allá del estrecho alcance de la ciencia de la gestión: ideas de geografía económica, sociología económica, ciencia política, economía urbana e incluso la economía del comportamiento se han utilizado para comprender lo que se necesita para crear las condiciones en las que puedan prosperar actividades como las representadas por la ESS (Barco-Serrano et al., 2019, p. 9).

Siguiendo dicho planteamiento, los ecosistemas para la ESS incluyen leyes y regulaciones, capital y finanzas, mercados, recursos humanos, sis- 
temas de apoyo, redes, etc. Así, para construir un ecosistema fuerte para la ESS, la co-construcción de políticas públicas y la gobernanza participativa también son factores muy importantes.

$\mathrm{Al}$ promover la ESS a través de ecosistemas adecuados para las organizaciones de la ESS, se podrían lograr ideas innovadoras para el futuro laboral. Con sus valores sociales, democráticos y su naturaleza equitativa, las empresas de la ESS muestran cómo son lugares de trabajo sostenibles e inclusivos a pesar de los crecientes desafíos de la polarización, la innovación tecnológica, el desempleo y los empleos inestables.

El informe no llega a mostrar nítidamente una propuesta definida y sistematizada de un Ecosistema de ESS, centrándose en los aspectos financieros necesarios para desarrollar el ecosistema, tomando como ejemplo diversas realidades como son la de Québec, en Canadá, Italia, Marruecos, Ecuador o Corea del Sur que ilustran la necesidad de que los instrumentos financieros más utilizados por las organizaciones de ESS son aquellos que son coherentes y consistentes con sus objetivos específicos y su ritmo de desarrollo, alejándose de la búsqueda de financiación externa de la cultura financiera dominante (Barco-Serrano et al., 2019).

En cuanto a los actores del ecosistema, serían las Cooperativas, Asociaciones, las asociaciones de beneficio mutuo (o mutualidades), las fundaciones, las empresas sociales y las asociaciones sin ánimo de lucro. En la siguiente figura se muestra el esquema de entidades de ESS.

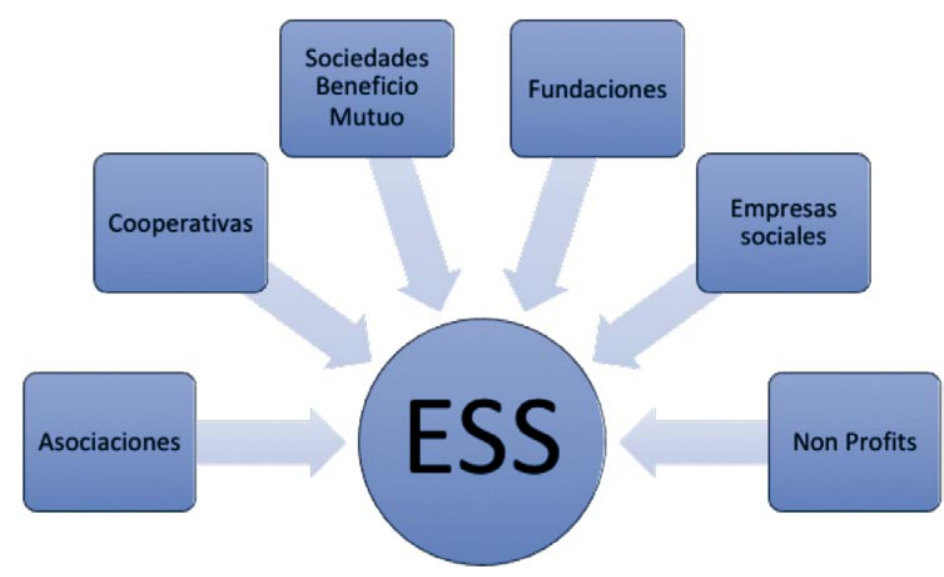

Fuente. Adaptación del autor, de la figura de la Organización de Desarrollo Industrial de Naciones Unidas (2017) en Arcos-Alonso (2021).

\section{Figura 1}

Entidades de ESS 
Como conclusión lanza varios elementos de interés en relación a la conceptualización del ecosistema:

Los ecosistemas podrian, potencialmente, ser evaluados desde otros puntos de vista alternativos a los flujos internos y externos de variables relevantes como información, poder, organización, recursos, por ejemplo. Desde esta perspectiva, sería importante identificar el tamaño del ecosistema (si hay un número suficiente de participantes) pero también cómo está organizado, es decir, si el flujo de información y recursos es coherente con el objetivo de producir un impacto social beneficioso o, más específicamente, para aumentar las capacidades de los actores de la ESS para lograr tal impacto en forma de desarrollo local, la lucha contra la pobreza, la provisión de empleos decentes o la facilitación de una distribución más justa de la creación de riqueza. Además, se debe tener en cuenta también que los ecosistemas no son sistemas estáticos, sino que están en constante cambio. Igualmente, existen propuestas interesantes que surgen de la ecología humana, la ecología económica y otras disciplinas que pueden abordar estos flujos y que podrían ser adecuadas para los análisis de ecosistemas de ESS. (Arcos-Alonso, 2021)

Por último, se toma en consideración el hecho de que la Economía Social y Solidaria está íntimamente ligada al desarrollo local, siendo capaz de reflejar componentes socioculturales en su propio contexto, además de proporcionar soluciones adecuadas a cada caso. Barco-Serrano et al. (2019) toma como referencia a Cicciarelli, Meglio, Franchini y Salvatori (2017, p. 3) cuando afirma que:

el desarrollo local no es sólo el resultado, en un lugar dado, de un proceso más amplio de crecimiento económico. Más bien, es un lugar en el que interactúan factores históricos, sociales y culturales especificos para generar un proceso endógeno que depende de la capacidad de los actores locales para organizar y regenerar respuestas a sus propias necesidades.

Finalmente, el informe subraya la relación entre los factores del desarrollo local antes citados y el sistema productivo de un territorio. La Economía Social y Solidaria y sus entidades, al ser participativas y democráticas en su gobernanza, tienen mayor capacidad de interaccionar con los agentes públicos en lo que concierne a dar respuesta a problemas de integración social. A resultas de ello, dichas entidades se erigen como las más capaces de responder a las demandas de bienes y servicios a nivel local. Tal y como aducen Borzaga y Tortia (2009), dado que la producción de «bienes cuasi públicos» y de bienes y servicios de interés general se basa en la confianza y la participación, las formas de gobernanza colectiva que caracterizan a las organizaciones de ESS pueden ser más eficientes y eficaces que 
las formas de gobernanza más tradicionales, basadas en la jerarquía o en la burocracia, consiguiendo sostener el desarrollo endógeno a medio y largo plazo.

\subsection{Las empresas sociales y sus ecosistemas en Europa}

En este apartado se presenta una revisión del informe elaborado por la Comisión Europea en el año $2020^{5}$ sobre las empresas sociales y sus ecosistemas en Europa. En él se analizan los ecosistemas de los entonces veintiocho países de la Unión Europea junto a otros siete países europeos. Para ello, partiendo de la definición de la Red EMES de empresa social, se ha hecho una adaptación que permite el reconocimiento de los diferentes contextos territoriales de los países en estudio, al tiempo que se utiliza como criterio de inclusión o no en la categoría de empresa social, que las empresas analizadas respondan a tres dimensiones: económica, social e inclusiva y de gobernanza.

El mapeo resultante recoge datos de las empresas referidos a los siguientes aspectos: (1) los antecedentes históricos y las condiciones del surgimiento de empresas sociales; (2) la evolución del concepto y la política nacional existente y el marco legal para la empresa social; (3) la escala y características de la actividad de la empresa social; (4) las redes y mecanismos de apoyo mutuo; (5) la investigación, educación y desarrollo de habilidades y, (6) los recursos disponibles para las empresas sociales (Comisión Europea, 2020).

En el informe se reconoce el impulso dado al desarrollo de las empresas sociales por la Economía Social (ES), y añade el término de "solidaria» a aquéllas que persiguen objetivos de interés general admitiendo que existe una mayor pluralidad de agentes y agencias interesadas, por lo que:

Bajo su perspectiva no existe gran diferencia respecto a las Empresas Sociales desde un enfoque amplio, salvo que las de Economía Social se centran en sus miembros, mientras que las Empresas Sociales (y solidarias bajo este concepto) se centran más en su aporte a la sociedad, visión, por otro lado, cercana a la conceptualización latinoamericana, francesa o española de la Economía Solidaria o a la ESS. (Arcos-Alonso, 2021, p. 266)

Así, desde una perspectiva analítica se propone un ecosistema de Empresas Sociales en relación a cuatro pilares, como se indica en la tabla 1:

5 Elaborado por la Comisión Europea para el Instituto Europeo de Estudios en Empresa Social y Cooperativa (EURICSE) y la red EMES. 


\section{Tabla 1}

Pilares del ecosistema de Empresa Social (incluyendo las de ESS)

\begin{tabular}{ll}
\hline Pilar & \multicolumn{1}{c}{ Descripción } \\
\hline P.1 & $\begin{array}{l}\text { La capacidad de auto organización de la ciudadanía, que favorece el surgi- } \\
\text { miento y el desarrollo de las empresas sociales de abajo hacia arriba }\end{array}$ \\
\hline P.2 & $\begin{array}{l}\text { El grado de visibilidad y reconocimiento de las empresas sociales (reconoci- } \\
\text { miento político y legal, a través de marcas privadas y auto-reconocimiento por } \\
\text { parte de las mismas) }\end{array}$ \\
\hline P.3 & $\begin{array}{l}\text { La capacidad de acceder a diferentes tipos de recursos (para el establecimiento } \\
\text { exenciones fiscales y beneficios fiscales) }\end{array}$ \\
\hline P.4 & $\begin{array}{l}\text { El desarrollo de la investigación, de oportunidades educativas y de habilidades } \\
\text { diseñadas para mejorar las ventajas competitivas de las empresas sociales para } \\
\text { responder a necesidades económicas y sociales }\end{array}$ \\
\hline
\end{tabular}

Fuente. Elaboración propia.

El ecosistema, por tanto, estará formado por la interacción entre todos estos factores. En la siguiente figura podemos ver el esquema del ecosistema de Empresas Sociales:

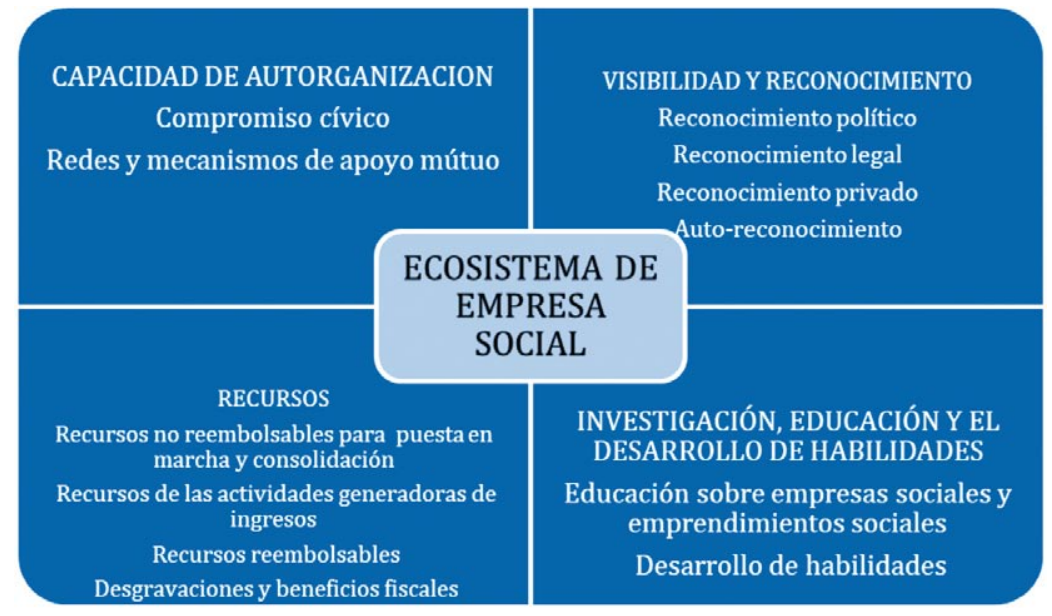

Fuente. Comisión Europea, 2020.

Figura 2

Esquema del Ecosistema de Empresas Sociales 


\section{Pilar 1. Capacidad de auto organización}

Este pilar se concreta en el desarrollo del Compromiso Cívico y la existencia de Redes y mecanismos de apoyo mutuo. El Compromiso social y civico, dado por el aumento de la participación ciudadana, refuerza y amplía la Empresa Social, Las Redes y mecanismo de apoyo mutuo, destacando la relevancia que han tenido tanto los movimientos cooperativos y las redes, así como las nuevas leyes y políticas adaptadas a las Empresas Sociales (caso de España). Se subraya que las redes son en sí mismas un mecanismo crucial de apoyo mutuo para crear y apoyar otros tipos de mecanismos de apoyo mutuo. - Por ejemplo, marcas privadas, premios, oportunidades de financiación, espacios de trabajo conjunto, etc.)—.

\section{Pilar 2. Visibilidad y RECONOCIMIENTO}

Se identifica la visibilidad de la empresa social y su reconocimiento a cuatro niveles: político, legal, privado, auto reconocimiento.

a) El reconocimiento político viene dado por la creación de unidades ministeriales, departamentos tanto de carácter central como regional o municipal con el objetivo de promover empresas sociales. Reformas en el ámbito del bienestar, empleo, contratación pública, por ejemplo, implican un reconocimiento de estas empresas como proveedoras de servicios de interés general. Por otro lado, algunos países tienen estrategias políticas específicas entradas en la economía social o empresa social, lo que implica su reconocimiento (Comisión Europea, 2020).

b) En cuanto al reconocimiento público a través de leyes, estatus y esquemas de acreditación, se observa que un grupo de países han introducido en su legislación iniciativas específicas para empresas sociales, y otros carecen de una regulación completa, como es el caso de España.

c) Algunos países, además del reconocimiento público mencionado, tienen un reconocimiento privado a través de marcas, sellos y certificaciones. Esto implica un aumento de la responsabilidad social del sistema económico, lo que contribuye a mejorar el entorno general en el que operan las empresas sociales. Como ejemplos, se recoge el Balance del Bien Común; Fairtrade, Ecocert, Fair for Life o los sellos de la Organización Mundial de Comercio Justo.

d) El auto-reconocimiento es un elemento básico y fundamental para el propio desarrollo de la empresa social. Aunque limitado todavía, por la falta de una cultura valorativa de iniciativas de empresa social, muy diversas, y con poca tradición de unir sus voces. 
En resumen, se puede afirmar que el impacto del reconocimiento de la empresa social es irregular. Puesto que, aunque el reconocimiento político y legal ha ayudado a visibilizar estas empresas que se han dado a conocer por la ciudadanía, las adaptaciones legales consiguientes, sin ventajas fiscales, no han llegado a ver este tipo de empresas como alternativas de emprendimiento válidas.

\section{Pilar 3. AcCeso a los Recursos}

En el informe se afirma claramente que el acceso a los recursos es fundamental para el desarrollo y consolidación de la actividad empresarial. Sin embargo, para la empresa social este acceso a recursos financieros es más complejo, ya que no buscan lucro para las personas o instituciones financieras, sino impacto social positivo, lo que es más difícil de cuantificar. Estas empresas, a diferencia de las convencionales pueden contar con un tipo de recursos adicionales, ya sean privados (humanos, como voluntarios, y financieros, como donaciones) o públicos (incluso en forma de ventajas fiscales específicas). Sin embargo, estos recursos pueden ser insuficientes o inestables. Es necesario, por tanto, acompañar al despliegue de las Empresas Sociales de un Ecosistema Financiero adaptado a sus particularidades.

Con ello, se hace referencia a la existencia de recursos no reembolsables para iniciar y desarrollar las empresas; subvenciones públicas y subsidios para la creación y consolidación de empresas sociales; contribuciones privadas tanto de recursos humanos (voluntariado incluido) como de financieros; actividades que generen ingresos para cubrir costos y excedentes para apoyo de inversiones: mantener relaciones fluidas con el sector público y acceder a la contratación pública; mantener relaciones con actores privados, tanto individuales y colectivos, como con otras empresas para generar nuevos mercados relacionados con nuevas formas de turismo, agro negocios sostenibles o economía circular, entre otros; la disponibilidad y el uso de recursos financieros reembolsables; desgravaciones y beneficios fiscales y; por último, en todos los informes nacionales e internacionales, se confirma la necesidad de aumentar la investigación y la capacitación. Se hace necesario, por tanto, incorporar la dimensión de emprendimiento social en la educación empresarial. Este último apartado, conforma el núcleo fundamental del cuarto pilar, por su relevancia para el desarrollo de la empresa social.

\section{Pilar 4. INVESTIGACIÓN PARA AVANZAR EN LA CIENCIA Y LA FORMULACIÓN DE POLÍ́TICAS}

La investigación sobre empresa social se ha ido consolidando como un campo de investigación científica, a partir del desarrollo de la innovación 
social como campo de estudio en la década de los 2000. Aunque fragmentada, principalmente descriptiva y clasificatoria, el desarrollo de numerosos proyectos de innovación social y el emprendimiento social complementaron la investigación sobre la empresa social al arrojar nueva luz sobre el poder transformador de tales entornos institucionales desde perspectivas nuevas.

Como se ha indicado en el apartado anterior, se hace necesario un desarrollo adecuado de la educación y la formación en empresas sociales. En la actualidad, aunque existe una variada oferta educativa (presencial, semipresencial y online), desde cursos y módulos hasta cursos de Grado y Postgrado que incluyen aprendizaje permanente; sin embargo, se hace necesaria una mayor consolidación (Comisión Europea, 2020).

Por último, se incide en el desarrollo de capacidades de las Empresas sociales. En la actualidad existe una variedad de programas con financiación tanto pública como privada (Comisión Europea, 2020), así como premios que incluyen formaciones para la capacitación en habilidades necesarias para el desarrollo de la empresa social y de las redes, que pueden llegar a incluir parte de la financiación o acceso a posibles financiadores. Cuestiones como la viabilidad financiera, el impacto social y la innovación tienden a ser objetivos para quienes participan.

A pesar de ello, se precisa aumentar tanto la investigación, que ha de ser más crítica y transformadora, como la educación que ha de estar más acorde con los retos que la sociedad está planteando en el momento actual: crisis económica, social y sanitaria. La educación y la investigación se consolidan como los pilares fundamentales para el desarrollo social.

\subsection{Sistemas locales de Economía Social y Solidaria (SLESS)}

La hegemonía capitalista global que impera en la actualidad provoca que las empresas compitan con el entorno productivo e institucional del que forman parte. Sin embargo, se está dando una revalorización de lo local, entendiendo esto como el nivel territorial donde "la proximidad física favorece el intercambio de información, la colaboración, una cultura propia y el aprendizaje colectivo entre los agentes económicos, la sociedad civil y las administraciones» (García-Jane, 2013, p. 189), lo que pone de manifiesto que el hecho de que exista un tejido empresarial numeroso y dinámico en el municipio o la comarca favorecerá la resolución de la mayoría de problemas sociales que un territorio determinado pueda padecer.

Surge así el término de Sistemas Locales de Economía Social y Solidaria (SLESS) como resultado de las sinergias creadas entre la ESS y 
el desarrollo local y los procesos de renovación territorial, es decir, de las iniciativas propuestas alrededor de una agenda territorial cuyas bases son la gobernanza participativa y la construcción conjunta, tanto pública como privada, de políticas locales (Villalba-Eguiluz y Pérez de Mendiguren, 2019; Villalba-Eguiluz, Egia, Pérez de Mendiguren, 2019). La experiencia de los SLESS se ubica en el territorio del País Vasco, y para su propuesta se han tomado como estudio de caso agencias de desarrollo, proyectos de desarrollo y entidades locales, con mayor o menor relación con las dos redes de ESS referentes del territorio: REAS Euskadi y Olatukoop.

La finalidad de estos SLESS es la creación de espacios que favorezcan la intercooperación empresarial atendiendo a la mencionada agenda territorial, para que se produzca una verdadera transformación a nivel económico, social y territorial. Esto se ha conseguido en algunos proyectos en los que los grupos de empresas reunidos poseían una serie de características propias comunes como eran: formar parte de ESS, provenir de oleadas distintas y haber participado en proyectos de la misma comarca. Además, de reflejar cierto grado de corresponsabilidad social en su labor diaria. Como relataban Villalba-Eguiluz y Pérez de Mendiguren (2019) y Villalba-Eguiluz, Egia y Pérez de Mendiguren (2019), los procesos amparados en sistemas locales de ESS muestran cierto potencial para erigirse como un eje de gobernanza territorial relevante, el cual puede diseñar los principales caminos por los que discurrirá el plan de desarrollo socioeconómico local futuro. Sistemas locales de ESS que se caracterizan por primar la innovación, sostenibilidad, equidad e inclusión, lo que denota la apuesta realizada por un sistema económico con potencial transformador.

Luego, el objetivo no es sino relacionar y coordinar las distintas acciones, iniciativas y estrategias de los diferentes agentes que intervienen en el territorio: Administración Pública, empresas y el propio tejido social y asociativo. Todo ello posibilitará la construcción de una agenda territorial común que promueva la transformación social, generando así un Sistema Local de Economía Social Solidaria «resiliente».

En definitiva, ante un contexto donde las políticas convencionales de creación de empleo y riqueza resultan inútiles, iniciativas vinculadas a nuevas formas de desarrollo y de economía pueden «preservar los niveles de bienestar de las mayorías sociales, al tiempo que gestan el embrión de una nueva sociedad y empodera a esas mayorías para que se movilicen hasta conseguirla» (García-Jané, 2013, p. 193). Si además estas nuevas iniciativas son acompañadas de cambios culturales en las políticas y en las instituciones, su poder de actuación puede ser aún mayor. Sin embargo, todavía es limitado el desarrollo de la ESS en el ámbito local. 


\subsection{Redes solidarias}

El concepto de «Red» remite a las relaciones que mantienen diferentes actores. Hablar de red solidaria añade la forma de ser de estas relaciones, que implican, normalmente, a entidades de pequeño tamaño, auto gestionadas, de propiedad social, con un marcado carácter comunitario, que cooperan en su desarrollo productivo (Moran-Esparza, 2008). Por su parte, Castilla-Carrascal (2014) añade que en este tipo de redes se promueve la solidaridad entre las personas organizadas en estas entidades o grupos, para garantizar un beneficio colectivo a partir de una producción y distribución horizontales. En esta misma línea, Mance (2008) afirma que el intercambio de bienes, facilita la expansión de la red, lo que redunda en el beneficio comunitario. Tiene, además, un doble objetivo: favorecer la sostenibilidad de los emprendimientos y propiciar el desarrollo territorial (Franca y Cunha, 2009), para lo que construyen circuitos propios de producción, distribución y comercialización creando una nueva regulación económica (Castilla-Carrascal, 2014).

Una de las características más reseñable de las redes es que asienta sus acuerdos en principios y valores éticos, en unos principios que pueden ser intensivos, extensivos, sistemas abiertos, así como diversidad, integridad y retroalimentación (Mance, 2008). Otra característica que permite identificar a las redes solidarias como modelo alternativo para el desarrollo social, es que la toma de decisión sobre su crecimiento y acceso a nuevos mercados se basa en el consenso, solidaridad y compromiso entre quienes participan en el sistema (Moran-Esparza, 2008). A estas características se pueden añadir la descentralización, la gestión participativa, la coordinación y la regionalización para garantizar la autodeterminación y autogestión de la red. Una gestión que será democrática en todos los aspectos (Mance, 2002).

Además, se observa cómo las redes interactúan a través de los denominados flujos, que pueden ser de tipo material (compras y ventas de elementos), de información (divulgación de contenidos, transferencia tecnológica) o recursos que fluyen por la red favoreciendo la viabilidad de los procesos (Castilla-Carrascal, 2014), En la tabla 2 se puede ver la relación entre los principios de las redes solidarias y los flujos de las mismas.

Así, las redes solidarias refuerzan la identidad del mercado a través de determinadas prácticas basadas en el comercio justo y solidario, Además, su sostenibilidad económica requiere de una planificación, implementación y control de los flujos de las redes que, en última instancia, redunden en la mejora de los de ingresos y de la reinversión (Melo-Lisboa, 2004). 
Tabla 2

Principios y Flujos de las redes

\section{PRINCIPIOS DE LAS REDES}

\begin{tabular}{|c|c|}
\hline Principios & Descripción \\
\hline $\begin{array}{l}\text { Sistema } \\
\text { abierto que se } \\
\text { autorreproduce }\end{array}$ & $\begin{array}{l}\text { Se auto crea, conecta grupos y realiza la articulación entre ellos } \\
\text { y fortalece cada grupo en particular por los intercambios que } \\
\text { ocurren. }\end{array}$ \\
\hline Intensiva & $\begin{array}{l}\text { Cada unidad de la red es intensiva con el fin de alcanzar e in- } \\
\text { cluir un mayor número de personas en el lugar donde actúa. } \\
\text { Esto puede significar el surgimiento de otros pequeńos nódu- } \\
\text { los en una región específica, articulados entre sí y conectado a } \\
\text { la red en general. }\end{array}$ \\
\hline Extensiva & $\begin{array}{l}\text { Extender la red a otros territorios colaborando en el surgi- } \\
\text { miento de nuevas unidades y en su desarrollo, ampliando el al- } \\
\text { cance de la red y fortaleciendo su conjunto. }\end{array}$ \\
\hline Diversidad & $\begin{array}{l}\text { Una red debe ser capaz de conectar la diversidad e integrar las } \\
\text { acciones de diferentes esferas, es decir, articular y fortalecer } \\
\text { cada nódulo manteniendo un flujo constante entre ellos. Ello } \\
\text { para poder crecer de forma creativa. }\end{array}$ \\
\hline Integridad & $\begin{array}{l}\text { Todos los objetivos de la colaboración solidaria que defienden } \\
\text { los diferentes nódulos de la red se asumen por el conjunto de } \\
\text { sus nódulos. Eso significa que contribuye en la ampliación de la } \\
\text { intensidad y extensivita y contribuye a fortalecer toda la red de } \\
\text { colaboración solidaria. }\end{array}$ \\
\hline Retroalimentación & $\begin{array}{l}\text { Fortaleciendo el conjunto de la red en la medida en que se di- } \\
\text { versifica en sus flujos y genera nuevas transformaciones en cada } \\
\text { nódulo, en particular, y en la red como un todo. }\end{array}$ \\
\hline
\end{tabular}




\section{FLUJOS DE LAS REDES}

\begin{tabular}{|c|c|}
\hline Flujos & Descripción \\
\hline Saberes & $\begin{array}{l}\text { Representa aquellos conocimientos que existen en el interior de } \\
\text { las redes, los cuales contemplan las diferentes historias de vida, } \\
\text { formas tradicionales de producción y de comercialización. }\end{array}$ \\
\hline Poder & $\begin{array}{l}\text { Ejercicio democrático dentro de las redes, esto es, con la parti- } \\
\text { cipación de los integrantes del grupo en las decisiones internas. } \\
\text { Deben ser observados los puntos en los que está concentrado el } \\
\text { poder para las tomas de decisión. Posibilidad de participación } \\
\text { de todos los integrantes del grupo en los procesos de toma de } \\
\text { decisiones de los EES o de la red. }\end{array}$ \\
\hline Información & $\begin{array}{l}\text { La información es utilizada de modo diferenciado: ante todo, es } \\
\text { un medio para fortalecer la transformación social y económica } \\
\text { para una sociedad sustentable, solidaria, justa y diversa. Para } \\
\text { alcanzar ese objetivo se plantean cuatro objetivos: de coopera- } \\
\text { ción, conocimiento libre, autogestión y circulación sin concen- } \\
\text { tración. }\end{array}$ \\
\hline Materiales & $\begin{array}{l}\text { En el trabajo se consume energía, materias primas y agua, y al } \\
\text { final hay desperdicios. Es importante saber de dónde vienen y a } \\
\text { dónde van los flujos de materiales (¿de dónde viene la energía?; } \\
\text { ¿cuánto puede ser reaprovechado?). }\end{array}$ \\
\hline Productos & $\begin{array}{l}\text { En este flujo puede verse lo que acontece con los productos una } \\
\text { vez que están terminados. La logística usada para entregar al } \\
\text { consumidor o el punto de comercialización, cuáles son las rutas } \\
\text { y cuáles los centros donde se depositan los productos. }\end{array}$ \\
\hline Financieros & $\begin{array}{l}\text { Por dónde pasa el dinero, de dónde viene y hacia a dónde va. } \\
\text { En esos flujos es posible percibir cuánto de la riqueza se queda } \\
\text { en una comunidad. }\end{array}$ \\
\hline
\end{tabular}

Fuente. Castilla-Carrascal, 2014, basado en Mance 2008 y Tygel, 2010.

Desde la perspectiva de la «teoría de la complejidad y la filosofía de la liberación» (Mance, 2002), el significado y sentido de las redes solidarias son consecuencia directa de la reflexión de las propias prácticas desarrolladas por actores sociales implicados en las mismas. Se trataría de un elemento central y estratégico para la transformación del modelo económico capitalista.

Y ello, debido a que la idea de red incide en las conexiones que fortalecen las sinergias colectivas y en los movimientos de apoyo donde cada uni- 
dad permite el desarrollo de las otras. La consistencia de cada participante va a estar condicionada por la forma en que se integra en la red, por los flujos en los que participa y en el modo en que acoge y colabora con el resto de miembros (Mance, 2002). Así, las entidades que quieran participar en las redes solidarias han de reunir cuatro criterios: no debe existir en los emprendimientos formas de explotación laboral, opresión política o dominación cultural; deben preservar el equilibrio de los ecosistemas: destinar una parte significativa del excedente de los ingresos al desarrollo y expansión de la red y, por último, tener autodeterminación de los fines y autogestión de los medios. Como alternativa al capitalismo, las redes solidarias dependen, en gran medida, de la difusión del consumo solidario, de la reinversión de los beneficios y de la cooperación solidaria entre sus miembros.

En las últimas décadas, como resultado del desarrollo de una mayor conciencia social de temas como igualdad de género, equilibrio medioambiental o educación para todos y todas, han surgido diferentes redes y organizaciones que persiguen el ejercicio ético de libertades públicas y privadas. Para Mance (2002) ello significa una «nueva esfera del contrato social» (p. 3). Aunque se inician en el ámbito de la cultura y la política pronto se extrapola al campo económico, ya que se exige un "control democrático de la sociedad sobre la economía y la generación de flujos de información» (Mance, 2002, p. 4). El aumento de estas nuevas redes demuestra su enorme potencial para llevar a cabo nuevas prácticas sociales de producción y consumo alternativo. La continua reinversión de los beneficios en los emprendimientos proporciona más oportunidades laborales inclusivas al tiempo que se expanden las redes de productores y consumidores para el mejor funcionamiento del mercado. Y ello, con la finalidad de conseguir una distribución de la riqueza más equitativa, que hace que colectivos tradicionalmente excluidos, puedan incorporarse al sistema y retroalimentarlo. Como sostiene Mance (2002), el principio de diversidad implica promover la satisfacción de demandas individuales en función del «bien-vivir» de todas las personas, en lugar del lucro económico.

En las redes solidarias se sustituye la motivación de la ganancia por la búsqueda de la satisfacción de las necesidades consideradas por la mayoría. El concepto de riqueza se amplía incluyendo la riqueza emocional, mental y espiritual, y cambiando la idea de competición por la cooperación y el respeto mutuo (Arruda, 2004). La finalidad del sistema económico así resultante es lograr la integración del consumo, producción, comercialización y crédito en un «sistema armónico e interdependiente, colectiva y democráticamente planificado y administrado" (Mance, 2002, p. 8), de tal modo que se cubran todas las necesidades humanas de forma sostenible.

Estas redes solidarias, además de los cambios económicos, promueven cambios en la vida política, puesto que demandan una gestión más demo- 
crática del poder. Por ello, como se ha mencionado anteriormente, se rechaza cualquier modo de explotación de los y las trabajadoras, de expoliación de los y las consumidoras o de dominación política y cultural. Se sustituye, desde esta perspectiva política, el individualismo por la colaboración solidaria de manera que se alcance un ejercicio colectivo y personal de la libertad. Ello implica a nivel micro-político promocionar éticamente las singularidades, mientras que macro-políticamente requiere una metamorfosis estructural de la sociedad mediante diferentes herramientas democráticas de autogestión pública (Mance, 2002).

Junto a estas dos dimensiones (económica y política) en las redes solidarias existe un alto desarrollo en los ámbitos informativos y educativos. En el educativo, se defiende que las personas no sólo logren competencias requeridas por el mercado actual (de tipo tecnológico y habilidades técnicas), sino que también recuperen la autoestima, sensibilidad y otros elementos éticos para lograr un buen vivir de toda la sociedad. Ello exige proyectos educativos integrales y humanizadores. En lo relativo a la información, tan crucial en la sociedad actual, la red promueve un flujo solidario de información que contribuye positivamente al proceso de toma de decisiones de sus miembros (Mance, 2006). Adicionalmente, resulta necesario el desarrollo de otros instrumentos para satisfacer otras demandas de índole artístico y científico para ejercer la libertad individual (Mance, 2002).

Asimismo, impulsar la solidaridad en las redes supone una exigencia ética, un compromiso con la que Mance (2002) relaciona el buen-vivir de toda la ciudadanía. Aceptar la diversidad humana, ya sea étnica, religiosa, lingüística o cultural es un requisito básico para el necesario ejercicio ético de las libertades. Su promoción conlleva respaldar y asegurar las condiciones materiales, políticas, informativas y educativas necesarias para posibilitar una existencia ética y solidaria.

\subsection{Mercado social}

Los Mercados Sociales suponen una de las respuestas a las debilidades del modelo económico actual y vienen a romper, como afirman Crespo y Sabin (2014), «la máxima neoliberal del sálvese quien pueda y a costa de quien sea» (p. 175).

Según estos autores, los mercados sociales surgen a raíz de:

— La necesidad de reformar la configuración de los actuales sistemas económicos promoviendo relaciones de justicia socio ambiental. 
— La necesidad de crecer y desarrollarse mediante entidades que intercooperan y se apoyan mutuamente a fin de minimizar debilidades y aprovechar fortalezas.

- La intención de enfrentar y encauzar el desarrollo de organizaciones productoras de bienes y de consumidores conscientes y responsables a nivel individual y colectivo.

Ante las sucesivas crisis socioeconómicas sufridas desde el año 2008 surge la necesidad de plantear alternativas a un sistema económico como el actual que cuestiona su propia sostenibilidad. Es necesaria, por tanto, una propuesta de articulación de modelos de producción, distribución y consumo alternativos basados en principios de sostenibilidad.

Ante este sistema capitalista, muchos consumidores y emprendedores perciben la inercia hacia el consumo innecesario y la carencia de valores sociales y ambientales, pero no encuentran una alternativa viable en la que poder gastar su dinero o emprender. Este tipo de empresas son una alternativa real, pero necesitan de una intercooperación entre ellas, como dicen García-Jané (2012) y García-Jané y Suriñach (2019), creando redes de producción y una franja de consumidores intermedios y finales fieles que les permita no caer en la sobreexplotación, marginalidad o ser asimiladas a la empresa capitalista.

Askunze (2013), desde la Red de Economía Alternativa y Solidaria (REAS), desarrolla y desglosa este concepto de que la intercooperación es condición necesaria en el Mercado Social para su permanencia y expansión. Esta cooperación conjunta entre los agentes implicados debe darse al menos de tres formas: la primera es incrementar el consumo interno entre las entidades que forman parte del mercado social, logrando que crezcan las iniciativas de esta índole. La segunda tiene que ver con las alianzas entre entidades y actividades para aumentar el conocimiento, bien pueden ser cursos, charlas, debates, etc., donde se cree un espacio para aunar y compartir ideas y posibilitar el nacimiento de nuevas iniciativas. El tercero, pero no último, ya que pueden ir apareciendo nuevas formas de intercooperación en la práctica, es el referente a asumir como propios los proyectos asociativos de otros sectores, como pueden ser las finanzas éticas, soberanía alimentaria, energías renovables, cultura e información alternativas, etc.

Así, los Mercados Sociales son un instrumento que tiene reflejo en el proyecto de REAS (Red de Redes de Economía Alternativa y Solidaria). Esta asociación está formada por más de ochocientas entidades agrupadas en redes territoriales y sectoriales. Se encuentran, además, presentes en el ámbito internacional mediante RIPESS (Red Intercontinental de Promoción de la Economía Social y Solidaria). Con sus mercados sociales, desde 
REAS se persigue «interconectar las diferentes iniciativas económicas impulsadas en un circuito económico único, compartido y coherente con esos valores que comparten».

El desarrollo del proyecto de REAS se basa en tres pilares fundamentales tal y como ellas mismas establecen:

- Abordar el mercado como principal contexto de transformación, situando a las personas y la sostenibilidad en el foco de las relaciones económicas.

- Comunicar e impulsar la intercooperación entre las iniciativas locales de la economía social y solidaria.

- Replantear formas de organización que impulsen una economía más solidaria y justa, logrando la implicación de la población mediante un consumo responsable.

El término «mercado social» es definido por Askunze (2013) como «una red de producción, distribución y consumo de bienes y servicios y aprendizaje común que funciona con criterios éticos, democráticos, ecológicos y solidarios, en un territorio determinado, constituida tanto por empresas y entidades de la economía solidaria y social como por consumidores/as individuales y colectivos. Cuyo objetivo es cubrir una parte significativa de las necesidades de sus participantes dentro de la red y desconectar la economía solidaria de la economía capitalista, tanto como sea posible (pp. 114). Con esto se persigue que la red tenga una autonomía suficiente para cubrir las necesidades de sus participantes y lograr desconectarse de la economía capitalista. Desde la Xarxa d'Economia Solidària de Catalunya (XES, 2021), ven a los mercados sociales como una herramienta necesaria e innovadora para articular los diferentes agentes del circuito económico.

Bajo la premisa del apoyo mutuo el Mercado Social propone tres reglas:

— Cada elemento de la red se compromete a consumir dentro de la misma el máximo posible.

- Los diferentes miembros de la red se comprometen también a producir en su interior el máximo posible para ella.

— Los miembros de la red apoyan otros emprendimientos vinculados a ella a través de los excedentes financieros y económicos generados.

Estos Mercados Sociales proponen una articulación en redes de distribución y consumo de bienes y servicios basadas en principios éticos, democráticos, ecológicos y solidarios. La finalidad última es lograr que estas redes cubran significativamente las necesidades de sus miembros y separar la economía solidaria de la capitalista (Crespo y Sabin, 2014). 
Según estos mismos autores, existen cuatro elementos básicos que pueden ser los componentes mínimos que permiten reconocer dónde se produce una estructuración efectiva de un mercado social:

1. «Voluntad transformadora de las condiciones de mercado». El mercado social se caracteriza básicamente por su deseo de modificar las condiciones del mercado actual con el fin de que sea más inclusivo y democrático.

2. "Una comunidad implicada (consumidores/as empresas)». Esta consideración conlleva al hecho de que tras un mercado social debe existir una comunidad empresarial responsable socialmente, consumidores conscientes y otras organizaciones que cooperen entre sí.

3 «Proceso democrático de articulación». Se requiere incorporar mecanismos democráticos basados en la transparencia, de tal modo que asegure una participación efectiva de los distintos agentes y una gestión adecuada de los diversos intereses.

4. «Combinación de herramientas de visibilización, comercialización y de acceso a un consumo responsable». Los mercados sociales ponen en marcha diversas herramientas de manera complementaria con el objetivo de dinamizar los vínculos de intercambio de bienes entre sus miembros.

Por otro lado, es necesaria la puesta en marcha de herramientas específicas de cara a poder lograr los objetivos de los Mercados Sociales. La imagen colectiva del Mercado Social cobra relevancia en la medida en que supone una imagen colectiva que refuerza la idea de circuito solidario, proyectando un impacto de marca en la ciudadanía.

El catálogo común de productos y servicios procedentes de la economía social y solidaria es otro de los instrumentos al servicio de los mercados sociales. Junto a él otra herramienta primordial es la auditoría o balance social elaborado anualmente por las organizaciones colaboradoras para acreditar el nivel de cumplimiento de los distintos objetivos vinculados con los valores de la economía social y solidaria.

Las ferias solidarias son también una herramienta fundamental, dado que acercan el mercado a la ciudadanía y aumentan la visibilidad de los Mercados Sociales. Tal y como aducen Crespo y Sabín (2014) son relevantes desde la perspectiva de que dan a conocer a la sociedad el circuito económico alternativo y ponen al alcance de la misma un consumo alternativo.

Por otro lado, la propia organización de los Mercados Sociales es dispar en los diferentes territorios donde se asientan. En algunos casos el propio Mercado Social se dota de personalidad jurídica, mientras que en otros son las propias redes territoriales quienes asumen su desarrollo, éste es el caso de Euskadi, Navarra y Cataluña (Rodríguez Prieto, 2020). 
Estos nuevos modelos de articulación económica basados en los Mercados Sociales se están consolidando gradualmente. Sin embargo, aún tienen por delante importantes retos que afrontar para convertirse en una auténtica solución que modifique las relaciones de mercado y trascienda de los grupos de individuos convencidos a la necesidad compartida de un cambio en el modelo económico para garantizar la sostenibilidad. Entre los diferentes retos, destacan los siguientes:

— La escalabilidad es, quizás, uno de los mayores retos. Tal y como señalan Crespo y Sabín (2014) es preciso lograr que los proyectos de mercado social sean escalables, puesto que en caso contrario sus efectos transformadores tenderán a disminuir y circunscribirse cada vez más a circuitos endogámicos.

-Es necesario coaligar los intereses de un mayor número de empresas democráticas, así como de consumidores concienciados. En este sentido, Prieto (2020) nombra a las asociaciones de comerciantes como posibles aliadas, así como el alinearse con los $\mathrm{ODS}^{6}$ de cara a poder recabar el apoyo de más consumidores y administraciones.

-Otro reto tiene que ver con la mejora de los instrumentos de visibilización y comunicación de los Mercados Sociales, dada su importancia estratégica y los beneficios derivados para el resto de instrumentos. En este sentido, el uso de lenguaje sencillo y accesible para la ciudadanía es fundamental. Como anteriormente se mencionaba, el posicionar una marca común es relevante a la hora de generar valor y distinción a aquellas empresas sociales, que sea reconocible y valorada por quienes consumen, siendo sinónimo de calidad, respeto y dignidad económica (Crespo y Sabín, 2014).

- La innovación organizacional cobra, asimismo relevancia, habida cuenta de que las entidades de ESS pueden tener un claro potencial en términos de generar innovaciones en su lugar de trabajo (Spear et al., 2009; Bretos y Errasti, 2018) y en el territorio geográfico adyacente (Etxezarreta, Etxezarreta, Zurbano y Estensoro, 2015). En efecto, la innovación constituye un ámbito de experimentación y prueba para la construcción de un mercado alternativo donde reunir en un mismo escenario de discusión política y estratégica a consumidores y empresas. Asimismo, se precisa una definición del reparto de papeles entre la dinámica y acción propia de las Redes de ESS y

${ }^{6}$ Objetivos de Desarrollo Sostenible, también conocidos como Objetivos Mundiales, se adoptaron por todos los Estados Miembros en 2015 como un llamado universal para poner fin a la pobreza, proteger el planeta y garantizar que todas las personas gocen de paz y prosperidad para 2030. 
el desarrollo del proyecto de Mercado Social, con el fin de conseguir que se complementen e incrementen su alcance (Díaz-Foncea, Bretos y Marcuello, 2021).

- El incremento y mejora de los canales de financiación de las entidades son, asimismo, otro reto fundamental. La potenciación de la Banca Ética como brazo financiero de las entidades, así como la generación de otras fuentes orgánicas de financiación intra-entidad y por parte de las personas consumidoras son objetivos de cara a escalar los Mercados Sociales.

— La potenciación de sectores estratégicos. En palabras de Suriñach (2017) avanzar hacia un estado de «hibridación» donde se da el caso de que existen iniciativas consolidadas, con estructuras estables y herramientas y elevada intercooperación. Ello implica saltos de escala de las experiencias desde la zona de "profundización» (zona anterior donde existe mayor experimentación, compromiso político y escasa cantidad de gente implicada). Esta zona de "hibridación» demandaría el consolidar las experiencias que tengan una mayor relevancia en términos estratégicos (por ejemplo, entidades de tamaño medio que trabajen en sectores como la Banca Ética o la energía), facilitar la profesionalización e incentivar dinámicas de intercooperación y redes, donde participen Administraciones Públicas, movimientos sociales, y también con universidades (Arcos-Alonso, 2021, p. 426).

- Por último, se debe precisar que el desarrollo de la economía social y solidaria y de los mercados sociales tienen como reto continuar cerca de los planteamientos teóricos y prácticos de los movimientos sociales, debiendo retroalimentarse de estos movimientos, tales como la economía feminista, el ecologismo o el decrecimiento.

\subsection{Circuitos Económicos Solidarios}

En apartados anteriores, se ha visto cómo en la última década han cobrado impulso prácticas de mercado comunitarias, con cierta trayectoria histórica, basadas en principios de reciprocidad y redistribución. Estas actuaciones se han mantenido a pesar de ser corrientes minoritarias en el mercado, apoyando el fortalecimiento de una solidaridad democrática, expresada por las economías plurales (Godelier, 1998; Guerra, 2005; Jiménez, 2016). Concretamente, se puede afirmar que han sido los diferentes movimientos sociales los impulsores de modelos de desarrollo basados en la economía social, situando en ella la reproducción de la vida como núcleo fundamental. 
Personas y colectivos carentes de sus libertades económicas y sociales se unen para generar economías inclusivas, alternativas y que muestren resistencia a las dinámicas económicas tradicionales (Mance, 2006). Así, diferentes colectivos de la sociedad se organizan en redes para posibilitar el flujo de bienes que, a su vez, dan lugar a los denominados circuitos económicos solidarios.

Los circuitos económicos y solidarios se insertan en la base de la economía social y solidaria, dado que generan conexiones sociales y no sólo utilidades económicas para dar respuesta a las necesidades sociales, favoreciendo, de esta manera, la cohesión social (Contreras, Mancheno y Cifuentes, 2018). Plantean la acumulación de riqueza más allá del capital, incluyendo en la idea de riqueza el desarrollo humano y el aumento de capacidades individuales y sociales (Lopera y Mora, 2009). Se trataría, según Díez (2007), de crear una riqueza con base humana donde se tiene en consideración la capacidad de decisión de los individuos para crecer en grupo y se asienta en valores como la reciprocidad, el cuidado medioambiental y la distribución equitativa (Jiménez, 2016).

En consecuencia, desde estos circuitos se promueve la unión de las diferentes iniciativas y actores implicados de la economía solidaria, relacionados con ámbitos como las finanzas solidarias, el consumo responsable, el comercio justo y el turismo sostenible a fin de generar un «bien-vivir» en la sociedad (MESSE) ${ }^{7}$.

En definitiva, los circuitos económicos solidarios aparecen a raíz de la articulación social de algunas comunidades con experiencia colectiva que se unen en torno a objetivos comunes. Estas comunidades fueron reconocidas posteriormente por organizaciones no gubernamentales, gobiernos municipales y por algunas universidades, mientras que la participación del sector privado se basó en atender las nuevas preocupaciones de la sociedad, cobrando relevancia la noción de empresa ciudadana que articula el servicio a la comunidad (Lopera y Mora, 2009).

Por tanto, el concepto de "circuitos solidarios" surge en el seno de la economía social, poniendo de manifiesto los desafíos que enfrentan las organizaciones al fomentar circuitos que crean transformación social y política (Jiménez, 2016). El reto de la economía solidaria supone superar la sociedad de mercado actual, pero sin desprenderse totalmente de los mecanismos mercantiles, algo que según Guerra (2005) sólo será posible por medio de la creación de circuitos de intercambio solidarios entre emprendimientos, que facilitan la reproducción y mantenimiento autónomos del propio sistema. Así, los circuitos pueden considerarse como redes de co-

7 MESSE: Movimiento de Economía Social y Solidaria del Ecuador. 
laboración solidaria que conforman un sistema abierto que se auto reproduce (Mance, 2008).

Asimismo, y teniendo en cuenta que desde la economía social y solidaria se hace especial consideración hacia los colectivos excluidos de la economía de mercado, en el marco de los circuitos económicos solidarios encontramos iniciativas que dan respuesta a sus aspiraciones, respondiendo así a la necesidad de crear procesos de participación inclusivos y justos, como base de una nueva sociedad. Por ello, la propuesta desde estos circuitos es integrar factores económicos, políticos, sociales y culturales, así como a diferentes actores.

Pero, ¿cómo se puede definir qué son los circuitos económicos solidarios? A continuación, se recogen diferentes definiciones, que suponen aproximaciones al concepto.

Para Silva (2013) los circuitos económicos solidarios se caracterizan por su vinculación territorial y los define como «conjunto integrado de unidades socioeconómicas que se adscriben a criterios de la economía social, las cuales pueden ser conformadas a distintos niveles de agregación y tienen vínculos complejos con el entramado social, cultural y político del territorio» (Silva, 2017, p. 67). Por tanto, los circuitos económicos solidarios se podrán considerar como un nuevo actor político desde lo local, debido a que su actuación parte de procesos de producción y consumo interrelacionados. Además, se pueden identificar con flujos económicos de bienes que satisfacen necesidades de los individuos y que se hallan articulados bajo los fundamentos de la solidaridad (Jiménez, 2016).

Ramírez (2017) considera que un circuito económico solidario es un "conjunto coherente y predeterminado de decisiones y acciones orientadas hacia la creación, en un espacio comunitario específico, de un circuito económico concebido como un proceso organizado de todas las actividades y vocaciones económicas de la comunidad y los estamentos que la constituyen, en función de la generación y la distribución de la riqueza y el bienestar sociales» (p. 68). Para su consolidación es fundamental el potencial ciudadano, ya que es responsable de expresar las deficiencias y el malestar social en el ámbito económico, por lo que una de sus piezas fundamentales es el consumo.

Razeto (1993), por su parte, establece una definición más operativa de los circuitos económicos solidarios argumentando que se trata de un «flujo de elementos sustantivos desde unos sujetos económicos a otros, en un movimiento incesante y circular que lleva al establecimiento de relaciones económicas transitorias y permanentes entre sujetos que participan en la economía» (p. 257). Esta conceptualización, por tanto, dibuja a este flujo bajo una perspectiva relacional que se manifiesta como el escenario social donde tiene lugar la reciprocidad (Silva, 2013). Como ya se ha apuntado, 
en este proceso de circulación es importante la implicación de los distintos sujetos y entes económicos que participan en la producción, la distribución y el consumo.

Así, el desarrollo y promoción de estos circuitos requiere normas de convivencia que favorezcan los valores de la economía social tales como la reciprocidad o la complementariedad. Principios estos que se unen a los de redistribución, vinculación entre las personas y la naturaleza, organización y trabajo colectivo comunitario y, por último, la construcción de autonomía (Jimenez, 2016).

Los circuitos económicos representan diversos flujos interconectados, como un conjunto de vínculos económicos ordenados en forma de flujos concatenados en una serie reiterada (Razeto, 1994). En este contexto, se postulan como la principal razón del proceso en el que se definen las relaciones familiares, de cooperación entre trabajadores/as, de donación, de compensación, tributación y de efectos redistributivos (Lopera y Mora, 2009).

Tales articulaciones son más frecuentes en espacios coherentes con su sistema de valores (Arboleda y Lopera, 2004), por lo que se pueden encontrar más frecuentemente en comunidades que ejecutan proyectos comunes bajo algún interés colectivo. De esta manera, se puede reconocer claramente las relaciones de solidaridad, cooperación o donación en tales contextos. Especialmente, en el ámbito local se han acumulado una serie de prácticas vinculadas a los circuitos económicos solidarios, donde se presentan sujetos que construyen escenarios en los que adquiere significado la experiencia de barrio para producir bienes que sean distribuidos teniendo en cuenta las necesidades, aspiraciones y deseos de las personas para conseguir la dinámica del circuito (Lopera y Mora, 2009).

Sin embargo, no se puede dejar de reconocer que el éxito de los circuitos económicos solidarios depende, en cierta medida, del apoyo del sector público a la operativa de la red (Lopera y Mora, 2009). En efecto, en la génesis y desarrollo de un mercado solidario y realmente democrático, son fundamentales las relaciones que se instauren entre las entidades de la economía solidaria, el sector público y el sector privado. Tales vínculos se alcanzan gradualmente a partir de la conexión entre organizaciones de diferente índole en estructuras superiores que logran autonomía en función de su nivel de desarrollo (Razeto, 1994). De este modo, se consigue abarcar desde las cadenas productivas hasta los procesos de distribución, consumo y financiación, hecho que les permite poseer más autonomía frente a organizaciones capitalistas (Lopera y Mora, 2009).

Tal y como se apunta, el conjunto de organizaciones que componen los circuitos económicos solidarios ponen en evidencia que es posible orquestar la producción y los flujos de bienes y servicios en el circuito a partir de 
la autonomía del factor trabajo. No obstante, se reconoce la necesidad de apoyo para lograr mayores cotas de productividad y negociación que hagan posible una comercialización efectiva de sus producciones. Es por ello, que mientras las organizaciones constitutivas de los circuitos asumen sus responsabilidades en función de los presupuestos asignados, desde el sector público se da el apoyo en aspectos como la financiación y el acceso a tecnologías que garanticen a los circuitos una participación de calidad.

Sin duda, y como defienden autores como Lopera y Mora (2009), el acompańamiento público es indispensable para llegar a desarrollar una producción y comercialización en condiciones equitativas frente al sector privado. Pero, también es necesario que se visualice a las personas responsables de los circuitos, como gestores reconocidos de otra economía. Aceptando, así, que existe otra forma de producir en una sociedad, con iniciativas económicas de carácter asociativo, basadas en valores de solidaridad, autonomía y ciudadanía, gestión democrática, finalidad social y remuneración limitada del capital.

Es así que, la base del surgimiento de los circuitos económicos, sobre todo micro-regional y regional, está en los movimientos intercooperativos, que emergen de iniciativas basadas en la comunidad y en el factor trabajo (Ramírez, 2017). La teoría económica sostiene que la circulación económica se entiende como un proceso formado por numerosos flujos y vínculos económicos que se entrelazan unos con otros.

De esta manera, los bienes discurren entre los diferentes entes continuamente, sufriendo sucesivas modificaciones a lo largo de este proceso en permanente movimiento, desde que ingresan al proceso económico hasta que salen del mismo, experimentando en su interior sucesivas y diversas transformaciones. Tal relación da lugar, según Ramírez (2017) a unos circuitos que constituyen un conjunto de vínculos económicos unidos en enlaces de flujos. Por tanto, la base de un circuito económico está configurada por los recursos, necesidades, técnicas y bienes resultantes. De esta manera, el circuito económico utiliza los recursos de los que dispone y los transforma en bienes de consumo final mediante el factor trabajo y la tecnología.

Los circuitos económicos solidarios, como función, operan bajo la racionalidad particular de elementos que caracterizan la producción de bienes y que discurren por toda la corriente económica, fundamentalmente hacia las comunidades asociadas en entidades económicas solidarias. Esta estructuración asociativa será la que conseguirá la cimentación del sector solidario de la sociedad futura.

En suma, la configuración de los circuitos económicos solidarios posibilita la estructuración de las iniciativas transformadoras y del desarrollo alternativo a partir de diversos movimientos sociales cuyos planteamientos constituyen una crítica al modelo imperante (Razeto,1994). Con su desarrollo 
buscan lograr un cambio social a través de determinadas prácticas en las que se prueban modos alternativos de relacionarse, modelando así una nueva perspectiva de desarrollo alternativo solidario (Lopera y Mora, 2009).

\subsection{Sistema Económico Social y Solidario - SESS-}

Según Coraggio existe la necesidad de construir otra economía desde la economía sustantiva y un pensamiento crítico con el sistema actual, un entorno socioeconómico que afirme la racionalidad reproductiva que derive en un marco de instrumentos eficaces (Coraggio, 2015).

Asume que la solidaridad intra-organización es un valor en sí mismo, pero que, sin embargo, existe la necesidad de avanzar hacia una lógica «sistémica» con otros valores e institucionalidad diferente. Hay que trascender, por tanto, el ámbito de los microemprendimientos familiares, asociaciones e incluso grandes cooperativas para avanzar hacia la articulación a nivel meso, que se traduce en una mayor cooperación y complementación orgánica conscientemente acordada entre diversas organizaciones de un mismo territorio, sector o encadenamiento intersectorial (Coraggio, 2014, p. 40). En esta línea se explora un vasto conjunto de posibles actores que son la base desde donde se realizaría la acción territorial. Todos los actores comparten un componente de solidaridad y corresponsabilidad, de tal manera que cristalizan en movimientos de actores localizados que funcionan bajo lógicas sistémicas. Se denota, por tanto, la importancia que da el autor al territorio y sus particularidades propias desde la perspectiva de la economía (Arcos-Alonso, 2021). Para la consecución del Ecosistema de Economía Social y Solidaria traza una ruta compuesta por diferentes niveles de acción y pensamiento:

El nivel microeconómico está compuesto por emprendimientos mercantiles - o no- que comparten o tienen potencial para lograr el objetivo común de reproducción y que cooperan funcionalmente desde la solidaridad.

Estos son los diferentes tipos de microemprendimientos:

- Microemprendimientos mercantiles organizados en base a lazos familiares o sin ellos.

- Encadenamientos funcionales de hecho, poniendo como ejemplo a las relaciones de insumo-producto mediadas por el mercado o bien las situaciones donde se dan interacciones de intercambio recurrentes basadas en reglas de reciprocidad.

— Unidades domésticas y el conjunto de sus actividades económicas de producción y reproducción (por ejemplo: producción mercantil, producción para el propio consumo, combinación y distribución de ingresos de sus miembros, etc.). 
- Conjuntos de personas o entidades que cooperan entre sí de cara a conseguir un fin relacionado con sus reivindicaciones económicas sectoriales. Asociaciones voluntarias colectivas de segundo grado entre emprendimientos o unidades en lo referente a su economía, relativamente homogéneas y destinadas a potenciar sus acciones por efecto de su masa, que básicamente se corresponde con lo que se podría denominar como asociaciones de consumidores o productores, o incluso de crédito. En suma, conjunto de personas o entidades que cooperan entre sí de cara a conseguir un fin relacionado con sus reivindicaciones económicas sectoriales.

Al nivel micro la lógica de la solidaridad entre actores se da a nivel intra, y está vinculada a las necesidades de intercambio. Por lo tanto, no existe una visión constitutiva del mercado, sino que más bien meramente causal y necesaria.

Subiendo en la escala de nivel se encuentra el nivel meso-económico. No se plantea aún una solidaridad sistémica, sin embargo, se observa la potencialidad de que exista la visión compartida de mercados independientes y a la vez interrelacionados, dado que las redes de relaciones particulares sí incluyen al mercado. Asimismo, a este nivel es posible clasificar de manera sistemática conjuntos o sectores internamente homogéneos. También es posible determinar conjuntos interrelacionados que comparten condiciones de producción y reproducción donde cada uno es en función de los otros (Coraggio, 2015, p. 9). A nivel meso se actúa sobre:

-Conjuntos heterogéneos con potencial de complementariedad y generación de sinergias (usualmente) territoriales de relaciones intersubjetivas solidarias cotidianas de reciprocidad, en que se dan asociaciones libres y prácticas complementarias en base a la cooperación - no necesariamente formal- - Ello de cara a la resolución de necesidades compartidas y lazos derivados de diversas relaciones de afinidad.

- Comunidades étnicas: unidades complejas, que combinan unidades particulares (usualmente familiares) que participan de una misma comunidad originariamente constituyente.

El nivel macroeconómico sería el tercero, donde las políticas sectoriales o macroeconómicas son asumidas por el sector público. Parte desde una visión de una Economía Mixta de tres sectores - empresas de capital, unidades económicas solidarias de reproducción de la vida y sector público en sentido amplio cada una con sus propios objetivos (maximización de beneficios, reproducción y bien común, respectivamente-

Aduce Coraggio (2016) que a este nivel es nuclear el afinar la lógica sistémica de la propuesta mediante la concertación público-privada que se 
traduce en la co-construcción de políticas públicas, teniendo en cuenta los intereses propios de cada actor.

Por último, se contempla el nivel sistémico. Éste sería el nivel de mayor complejidad y riqueza, vertebrado por principios, valores, instituciones y prácticas generalizadas. Se trata de un nivel donde cobra relevancia la dimensión normativa, donde el Estado sea garante de derechos económicos y establezca las reglas y obligaciones que generen pautas de comportamiento alternativas vinculadas a la solidaridad. En este último punto de desarrollo sistémico se daría un cambio estructural donde lo social se imbricaría en lo económico, situándose la solidaridad en el centro del sistema.

Por otro lado, existen diferencias entre los niveles de acción y los alcances posibles que pueden llegar a lograr las prácticas de ESS. Se refiere a hasta dónde se puede llegar en escala, difusión, complejidad o centralidad de su lógica dentro del sistema (Coraggio, 2015). Estos alcances se plantean en cuatro tipos diferentes.

El primero se vincula al sostenimiento y generación de una multiplicidad de microemprendimientos mercantiles asociados internamente solidarios, pero no necesariamente entre sí. Entiende este nivel como una suerte de política social compensatoria de inclusión social, que genera procesos de solidaridad y que se puede desarrollar a nivel micro, micro/meso e incluso $\mathrm{micro} / \mathrm{meso} / \mathrm{macro}$.

El segundo tipo de alcance tiene que ver con construcción/promoción de subsistemas solidarios de producción y reproducción articulados intersectorial y/o territorialmente (Coraggio, 2015). Sobre una base asentada en el territorio, redes, asociaciones y cadenas mecánicas trabajarían bajo una lógica común pero todavía insertas en un sistema capitalista. Las acciones serían a nivel meso, pero bajo una perspectiva de alcance macro, apuntando, eso sí, a otro sistema económico.

En tercer lugar, se encuentra la generación inducida de una nueva estructura y equilibrios según el modelo macroeconómico. Apunta el autor a cambiar la matriz de pesos relativos y flujos agregados entre diferentes sectores, así como de sus relaciones de arrastre mutuo a nivel cuantitativo. Se trabajaría sobre variables de producción, insumos intersectoriales, consumo final e inversión, enmarcando el análisis en los tres sectores de la economía mixta.

Por último, aparece el alcance que trata sobre el cambio de paradigma y construcción de otra economía. En este umbral de alcance es necesaria la re-jerarquización de los mismos principios integradores de la economía, así como la apertura a nuevos actores de la economía social y solidaria. La economía pasaría a enfocar el propio acto económico hacia el objetivo de reproducción de la vida, alejándose de la lógica capitalista, logrando un modelo de producción integral de Sistemas de Economía Social y Solidaria. Sin embargo, es necesaria cierta cautela a este nivel, debido a la dificultad 
que conlleva la inducción de procesos de solidaridad a nivel micro/meso de manera precipitada.

Estratégicamente Coraggio plantea el priorizar el apoyo a la multiplicidad de emprendimientos mercantiles asociativos que hayan demostrado capacidad de sostenimiento y que sean generadores de empleo. Ahora bien, para ello es interesante realizar una discriminación entre niveles y alcances de cara a ubicar y potenciar las acciones de generación y desarrollo de formas solidarias de economía. En la siguiente tabla se recogen una combinación de niveles y alcances, mostrando de qué manera una acción es eficaz en relación a otra y de qué manera llegan a potenciarse entre ellas.

\section{Tabla 3}

Combinación entre niveles de alcance y acciones según Coraggio

\begin{tabular}{|c|c|c|c|c|}
\hline \multirow{2}{*}{ (Niveles de acción) } & \multicolumn{4}{|c|}{ Niveles de alcance } \\
\hline & Micro & Meso & MACRO & $\begin{array}{l}\text { Sistémico. } \\
\text { Otra economía }\end{array}$ \\
\hline Multiplicación de emprendimientos & $\mathrm{X}$ & $\oplus$ & $\oplus \oplus \oplus$ & $\oplus \oplus \oplus$ \\
\hline Articulación de Subsistemas & $\nabla$ & $\mathrm{X}$ & $\oplus$ & $\oplus \oplus$ \\
\hline Reestructuración de flujos & $\nabla$ & $\nabla$ & $\mathrm{X}$ & $\oplus$ \\
\hline Construcción de Otra Economía & $\nabla$ & $\nabla$ & $\nabla$ & $\mathrm{X}$ \\
\hline
\end{tabular}

$\oplus$ La eficacia de acción se potencia en el alcance superior.

$\nabla$ La concreción de acciones eficaces a este nivel requiere acciones del nivel inferior.

Fuente. Elaboración propia. Adaptación de Coraggio (2015).

La tabla 3 recoge los objetivos logrados (X) en cada uno de los niveles de alcance, de tal manera que a nivel Meso se consigue la Articulación de Subsistemas y se potencia el objetivo alcanzado en el nivel anterior $(\oplus)$. Es decir, se potencia la Multiplicación de Emprendimientos. Asimismo, los triángulos invertidos $(\nabla)$ implican cierta debilidad a ese nivel de alcance para conseguir esa acción. En el caso del nivel Meso se estaría hablando de la Restructuración de Flujos y de la Construcción de otra Economía, siendo, sin embargo, necesarias la concreción de acciones eficaces en este nivel Meso para que en el nivel superior (Macro) se pueda alcanzar la acción de Reestructuración de Flujos, por ejemplo.

Así, Coraggio (2016) propone una definición del sistema económico social y solidario (SESS). Define este sistema como un sistema histórico de instituciones, valores y prácticas (recurrentes, por costumbres, por eficacia 
comprobada, jurídicas...) mediante el cual cada comunidad, conjunto de comunidades o sociedad, organiza y coordina el proceso económico cuyos momentos son:

1. La producción racional de bienes y servicios bajo una pluralidad de formas de organización en el marco de un sistema de división social del trabajo según los principios de complementariedad, cooperación y capacidades humanas.

2. Distribución y redistribución de la nueva riqueza producida entendida como valores de uso para realizar las necesidades de todas las personas.

3. Intercambio justo entre personas, sectores y regiones, con predominio de la reciprocidad sobre la competencia.

4. Modos de consumo responsable con la naturaleza y la convivencia social.

5. Coordinación consciente y democrática del conjunto del proceso económico, combinando formas de decisión colectiva o mecanismos como el de mercado regulado.

\section{Diferentes características de las propuestas ecosistémicas alternativas al sistema hegemónico}

Las diferentes redes/circuitos, sistemas y ecosistemas comparten diversas variables de interés declaradas con mayor o menor exactitud en sus propuestas de construcción y despliegue. Ahora bien, en base a la literatura revisada pueden observarse distintos tipos de intensidad de implantación en las variables analizadas.

Basado en un análisis más extenso de las propuestas de despliegue ecosistémico de ESS (Arcos Alonso, 2020, 2021) se han identificado un total de veintitrés variables. El nexo común a todas ellas es la necesidad de contemplarlas de cara a la construcción, sostenimiento y despliegue de las mismas. Éstas, sin embargo, mantienen una incidencia diferente en la importancia de la aplicación de las variables.

Así, en la siguiente tabla se presentan por un lado los ámbitos/elementos clave que sustenta cada propuesta, su inspiración/es académicas, y por otro las diferentes variables identificadas y la intensidad de su aplicación en una escala de intensidad de menor a mayor, donde el color azul claro representa la menor intensidad y el color azul marino la mayor.

En definitiva, en la siguiente tabla 4 se recogen las diferentes propuestas ecosistémicas de ESS, ámbitos, inspiración e intensidad de aplicación declarada de variables para su construcción, sostenimiento y despliegue. 
ASIER ARCOS-ALONSO, AMAIA GARCIA-AZPURU

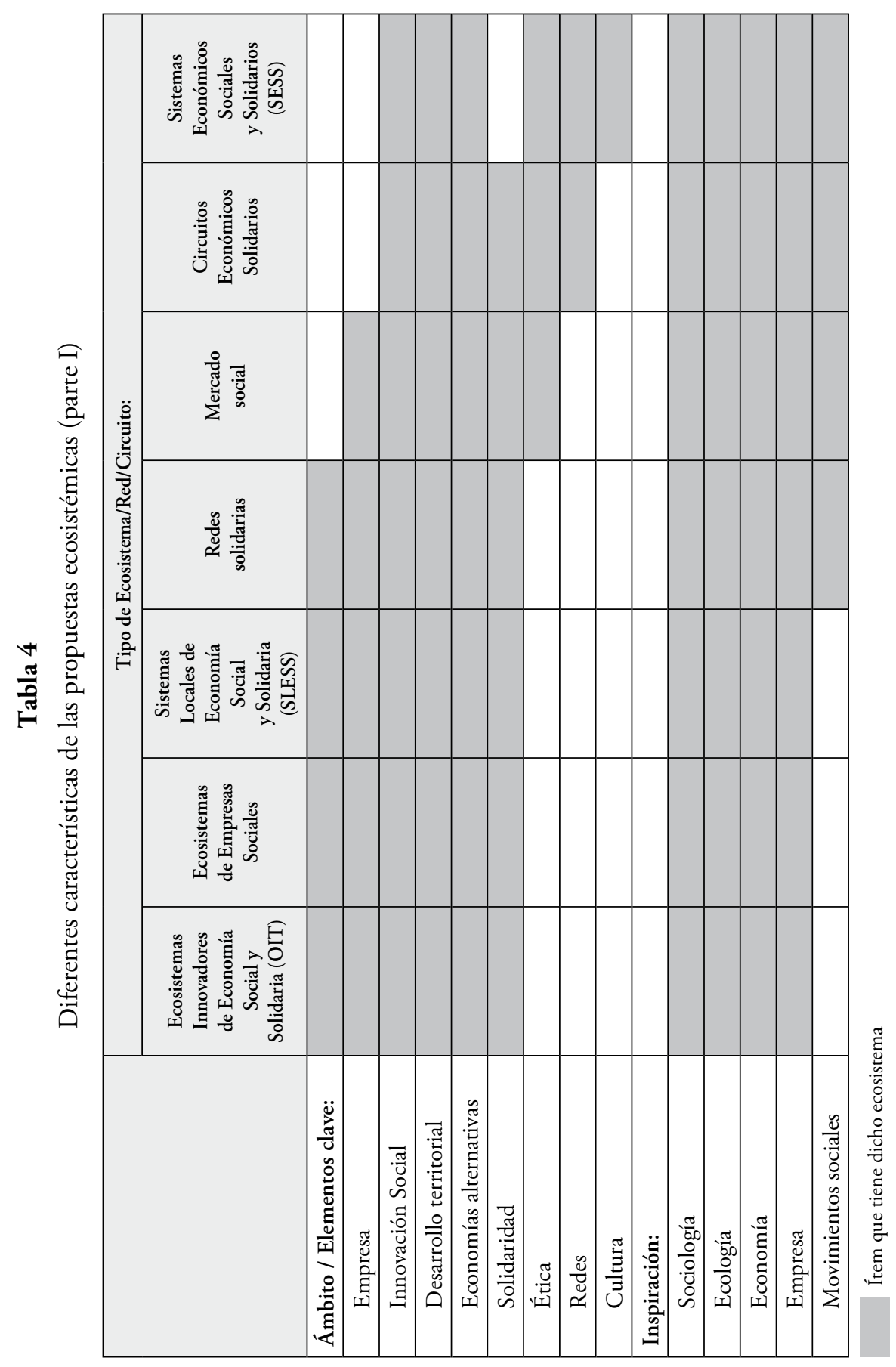




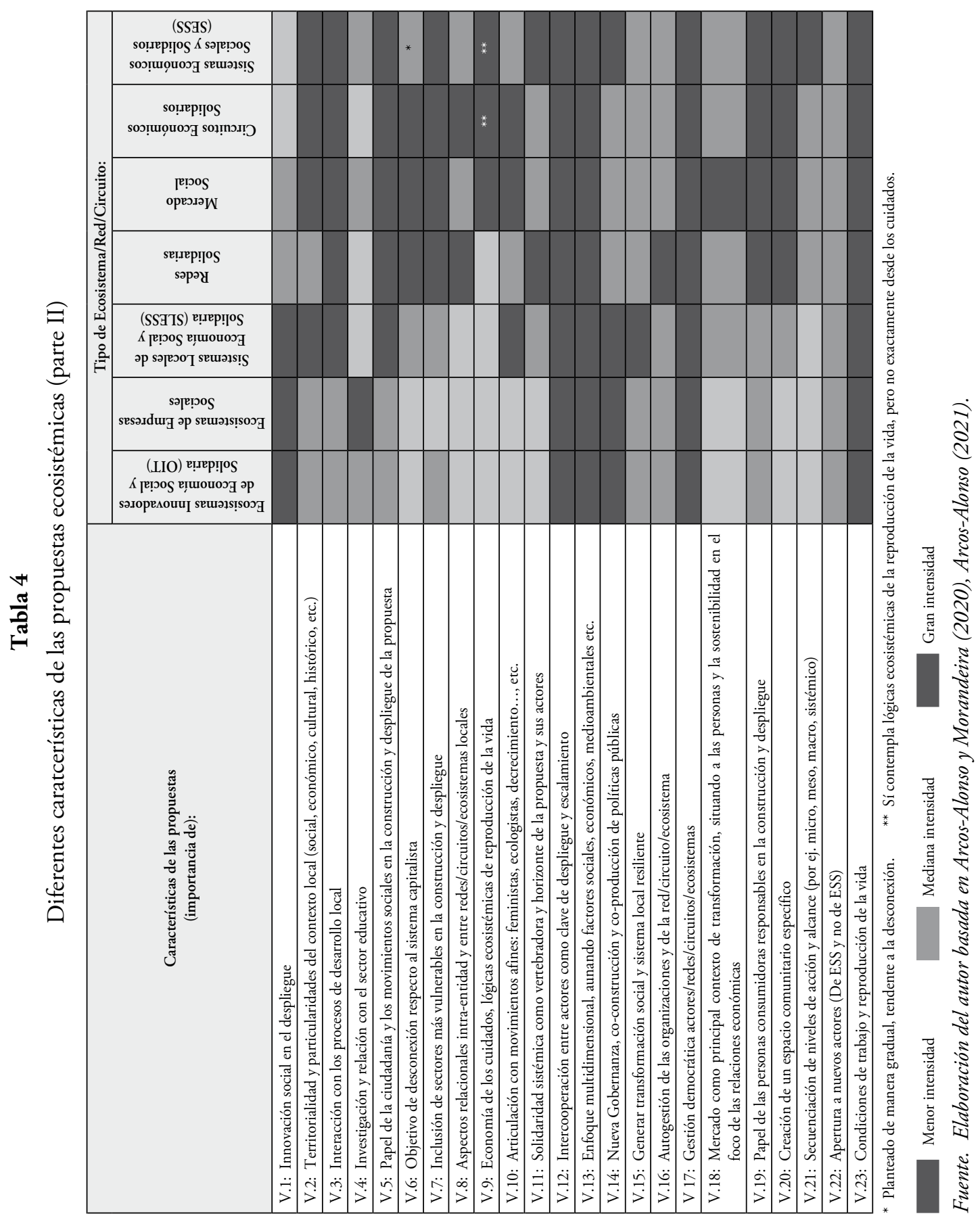


Como se puede observar en la tabla 4, y a modo de ejemplo, los movimientos sociales y la ciudadanía [V5] cobran un papel muy relevante e intenso en la construcción de los Ecosistemas de Empresas Sociales, los Circuitos Económicos Solidarios y el Mercado Social. En cambio, en los Ecosistemas Innovadores de Economía Social y Solidaria. la importancia de estos no se resalta de la misma manera, al centrarse más en las propias personas pertenecientes a los emprendimientos. Otro caso sería la articulación declarada con movimientos afines como son el movimiento feminista, ecologista o decrecentista [V10]. En esta ocasión, tanto los Mercados Sociales y los Sistemas Locales de Economía Social y Solidaria, identifican a estos movimientos como aliados naturales que hay que buscar y articularse. Otras propuestas, sin embargo, no resaltan tan nítidamente este papel de ellos.

Lo mismo se puede decir de las demás variables, como por ejemplo la importancia de la Innovación Social [V1], los aspectos relacionales [V8], de la territorialidad, cultura e historia de un territorio etc. [V2]. En unas propuestas se subrayan estos aspectos y en otras, sin embargo, no tanto, lo que, no obstante, no quiere decir que no lo contemplen, dadas las limitaciones del análisis, basado en fuentes secundarias de tipo descriptivo.

Asimismo, es resaltable que las propuestas coinciden en la importancia que tienen los procesos de intercooperación a la hora del despliegue y escalamiento estratégico de las mismas [V12]. De igual manera, en coherencia con la integralidad de los planteamientos, todas las propuestas adoptan enfoques multidimensionales de análisis de la realidad, incorporando factores sociales, económicos, medioambientales entre otros [V13]. También es alta la concordancia que tienen en relación a la importancia de asentar las propuestas en procesos de desarrollo local o territorial [V3].

En todas las ocasiones se encuentra concordancia en cuanto a la relevancia del papel de la ciudadanía de a pie y los movimientos sociales en la construcción y despliegue [V5], así como en la necesidad de plantear nuevos marcos de Gobernanza y abordar el cambio de relaciones con las administraciones públicas [V14]. Asimismo, la relevancia de las personas consumidoras responsables [V19] es asumida como importante por la mayoría de las propuestas. Y resultando también parecida concordancia en el énfasis que se le da a la necesidad de articular las propuestas con el objetivo de potenciar la inclusión de las personas más vulnerables [V7].

Sin embargo, se observa diferente intensidad declarada en cuanto a la importancia de tener en cuenta la economía de los cuidados y las lógicas de reproducción de la vida [V9] como elemento clave. Mientras que los Mercados Sociales asumen directamente la necesidad de incorporar al análisis esta variable proveniente de la economía feminista, otras propuestas no hacen tanto hincapié en ello. 
Por otro lado, se ven intensidades diferentes en cuanto a la necesidad de fomentar la investigación en los propios procesos de construcción, sostenimiento y despliegue [V4], así como el fortalecer los lazos con los sectores educativos [V4]. Los ecosistemas de Empresas Sociales, por ejemplo, subrayan nítidamente la importancia de esta variable.

Por último, existen matices a la hora de plantear abiertamente el objetivo de desconectarse del sistema capitalista [V6]. Mientras el Mercado Social tiene como uno de sus objetivos principales avanzar paulatinamente hacia esta desconexión, las Redes Solidarias apuntan a ello de manera más sutil y los Circuitos económicos Solidarios hablan de «superar la sociedad de mercado actual», aún sin desconectarse del todo. Por su parte, los Sistemas Económicos de Economía Solidaria apuntan hacia esta idea planteando, además, diferentes niveles de acción y alcance, mientras que otras propuestas no lo resaltan con tanta intensidad.

\section{Conclusiones}

Como se ha podido observar, existe una variedad de nomenclaturas que comparten el nexo común de ser propositivas para una economía alternativa al sistema económico capitalista imperante.

La primera conclusión es que ante los contextos complejos y cambiantes actuales se ha visto necesario proponer alternativas estratégicas estructuradas que avancen hacia el cambio estructural del sistema económico. Se ha dado un aumento progresivo en diferentes partes del mundo de planteamientos alternativos en clave ecosistémica. Estas propuestas son variadas y múltiples, debido al hecho de que cohabitan variedad de emprendimientos, actores, intereses, estructuras organizativas, fórmulas jurídicas y contextos en los que se desenvuelve la ESS.

Existen propuestas más adaptadas a contextos geográficos más restringidos, como los SLESS que centran su radio de acción en el ámbito del País Vasco, o los Circuitos Solidarios (e interculturales) que se centran en el ámbito geográfico andino. Por otro lado, surgen propuestas más abiertas como la de los Ecosistemas de Empresas Sociales, de ámbito europeo, o los Sistemas económicos de Economía Social y Solidaria.

No obstante, además del ámbito geográfico, es relevante poder ver la querencia desde diferentes instituciones, a nivel local, regional o internacional por avanzar en el cambio estructural de las realidades sociopolíticas y económicas, poniendo a la persona en el centro del acto económico.

El contacto con otros ecosistemas de ESS, otros agentes de ESS u otras economías alternativas es fundamental de cara a poder generar sinergias que alienten el desarrollo de un Ecosistema de ESS. Lo atomístico y la poca 
escalabilidad individual de los actores de ESS alientan el plantear esquemas de desarrollo donde la intercooperación y la solidaridad sistémica y ecosistémica sean nucleares. Así, el investigar y proponer esquemas de relación de nodos, redes, flujos y relaciones de intercambio a nivel económico, social y cultural, basados en valores como la equidad, redistribución, solidaridad y democracia parece ser fundamental en diferentes partes del mundo.

Los contextos en los que se quieren implantar las propuestas de despliegue de la ESS, tal y como sucede en un ecosistema biológico, están en constante cambio, luego las medidas y esquemas propuestos han de ser flexibles en tiempo y forma, lo que complejiza su despliegue. Diversas propuestas aluden a ello, aunque no llegan a proponer mecanismos correctores.

Por otro lado, existen limitaciones y retos inherentes a la propia idiosincrasia de la ESS y sus actores. Como se ha visto, lo central en la ESS es el ser humano con toda su complejidad. Y cuando en la base de la acción económica está la participación de las personas y las relaciones democráticas, los procesos de toma de decisión y concertación necesitan de más tiempo, lo que puede ser una dificultad en los tiempos que corren, donde se requieren respuestas y acciones rápidas. Además, aunque se compartan valores y principios, no siempre son suficientes para desarrollar estrategias coherentes y sostenidas en el tiempo (Arcos-Alonso, 2021).

Además, el despliegue y escalamiento de las propuestas plantean limitaciones ya que al crecer se hacen más complejos los flujos distributivos y sus impactos. Pueden aparecer algunas contradicciones, por ejemplo, cuando el aumento del mercado exige movimientos de bienes que pueden tener impacto medioambiental. Riesgo que se puede controlar con un Ecosistema de ESS local/regional, lo que, por otro lado, disminuye su potencial transformador ecosistémico (Arcos-Alonso, 2021). Como alternativa para preservarlo se plantea el trabajo en red muy articulado que, también ha de afrontar retos para demostrar su viabilidad y eficiencia, más aún en la realidad cambiante a la que se ha aludido.

El sistema capitalista tiene un gran potencial fagocitador de las iniciativas alternativas, por lo que cuando las entidades de ESS crecen, deben fortalecer su sistema de valores y principios, debido a que se hacen más complejas no sólo la toma de decisión, sino la transparencia interna, y corren riesgo de hacerse más opacos, por la presión del mercado.

Sin embargo, las entidades trabajan por mantener su capacidad de innovar, de dar respuesta a las necesidades de las personas como individuos y como colectivo, trabajando en red y estando presentes en sus contextos, lo que genera mayor reconocimiento y aceptación. Además, es importante no perder de vista la necesidad de trabajar de forma conjunta con las Administraciones Públicas. El reto está en configurar un espacio de gobernanza 
de la ESS, donde se trabaje desde la horizontalidad entre diferentes agentes públicos y privados, que sean capaces de construir y producir políticas públicas que respondan a las necesidades sociales.

Ello requiere de un nuevo marco relacional entre agentes, para lo que las experiencias y prácticas dentro de las entidades de ESS pueden ofrecer aprendizajes interesantes. En la ESS se intenta fortalecer las relaciones sociales de producción de bienes y servicios, que van a determinar los propios factores de producción. Son relaciones basadas en la confianza, la solidaridad, la reciprocidad. Si bien, este tipo de relaciones ideales pueden llegar a ser más difíciles cuando las entidades /sistemas/ ecosistemas son muy grandes, pensar en cómo llevar a cabo un proceso relacional satisfactorio en contextos más complejos es otro reto que se presenta en la ESS. Reto que habrá de afrontarse de manera multidisciplinar, considerando especialmente el potencial que tiene la educación y la formación para trabajar en contextos de cambio. Cambio que probablemente deba comenzar en el interior de la propia ESS, de sus agentes, con una reflexión profunda sobre los valores y principios que comparten y que les hace ser alternativa económica, para seguir con formación en economías alternativas tanto desde las universidades como los centros de secundaria.

También existe el reto de poner en valor ante la ciudadanía y en la estructuración estratégica de las mismas propuestas la economía de los cuidados y la importancia de las respuestas comunitarias, que se han revelado fundamentales para hacer frente a crisis como la sanitaria que se vive hoy en día con la emergencia de la pandemia del COVID-19.

Y por finalizar, y como línea futura de avance, una vez presentadas algunas de las conclusiones que se derivan de este estudio teórico cabría pensar en una investigación de interés que se centrara en el análisis y contraste empírico de las variables identificadas, estudiando sus correlaciones y contradicciones en el marco del abanico de propuestas ecosistémicas identificadas.

\section{Bibliografía}

Arboleda, O., y Lopera, L. D. (2004). Racionalidad de prácticas de Economía solidaria en Medellín en las últimas tres décadas del siglo XX. México-Medellín. Fundación Universitaria Luis Amigó Press.

Arcos-Alonso, A. y Morandeira, J. (2020). Ecosistemas locales de Economía Social y Solidaria. Una aproximación desde las entidades. Revista Iberoamericana de economía solidaria e innovación socioecológica. 3, 37-59.

Arcos-Alonso, A. (2021) Ecosistemas de Economia Social y Solidaria en el País Vasco. Colección tesis doctorales. Leioa. UPV/EHU. 
Arruda, M. (2004): ¿Qué es la Economía Solidaria? El renacimiento de una sociedad humana matrística. Ecología Política, 27 (1), 71-76.

Askunze, C. (2013). Más allá del capitalismo: alternativas desde la Economía Solidaria. Documentación social, 168, 91-116.

Barco-Serrano, S., Bodini, R., Roy, M., y Salvatori, G. (2019). Mecanismos Financieros para Ecosistemas Innovadores de Economía Social y Solidaria: resumen ejecutivo.

Bodini, R., Cicciarelli, L., Meglio, R. D., Franchini, B., y Salvatori, G. (2017). Putting the «Local» in Economic Development: The Role of the Social and Solidarity Economy Presentado en el IV Foro Mundial sobre Desarrollo Económico Local, Praia, Cabo Verde.

Borzaga, C. y Tortia, E. (2009). Social Enterprises and Local Economic Development. En: A. Noya (Ed.), The Changing Boundaries of Social Enterprises (195228) París: OCDE.

Bretos, I. y Errasti, A. (2018). The challenges of managing across borders in worker cooperatives: Insights from the Mondragon cooperative group. Journal of Co-operative Organization and Management, 6(1), 34-42.

Castilla-Carrascal, I. T. (2014). Redes económicas solidarias: el caso de Brasil. Cooperativismo \& Desarrollo, 22 (105) 55-65.

Climent, V. C. (2016). La economía social y solidaria en el siglo xxi: Un concepto en evolución. cooperativas, B corporations y economía del bien común. Oikonomics: Revista De Economía, Empresa Y Sociedad, 6, 6-15.

Comisión Europea/European Commission (2020) Social enterprises and their ecosystems in Europe. Comparative synthesis report. Borzaga, C., Galera, G., Franchini, B., Chiomento, S., Nogales, R., and Carini, C. Luxembourg: Publications Office of the European Union. https://bit.ly/3fC46wp

Contreras Día, J., Mancheno Ponce, D., y Cifuentes Vega, S. (2018). Tourist solidarity economic circuits a challenge of sustainability. RETOS. Revista de Ciencias de la Administración y Economía, 8 (15), 69-81.

Coraggio, J.L (2007a). ¿Es posible otra economía sin (otra) política?, en Coraggio, J.L. Economia Social, acción pública y politica (179-224). Buenos Aires: CICCUS.

- (2007b): Una perspectiva alternativa para la economía social: de la economía popular a la economía del trabajo, en Coraggio (ed.), La Economía Social desde la periferia. Contribuciones latinoamericanas (165-194). Buenos Aires: Altamira.

- (2014). La economía social y solidaria y el papel de la economía popular en la estructura económica. La economía Popular y Solidaria. El Ser Humano Sobre el Capital 2007-2013, 21-46.

- (2015). La Economía Social y Solidaria (ESS): Niveles y alcances de acción de sus actores (inédito). Recuperado de www. coraggioeconomía. org.

- (2016). La economía social y solidaria (ESS): niveles y alcances de acción de sus actores. El papel de las universidades. Economía Social y Solidaria: conceptos, prácticas y políticas públicas. Bilbao: Universidad del País Vasco-Hegoa. 
- (2017): Las tres corrientes vigentes de pensamiento y acción dentro del campo de la Economía Social y Solidaria (ESS). Sus diferentes alcances. https://bit.ly/3z1uYxA

Crespo, B. y Sabin, F. (2014): Los mercados sociales. La Economía Solidaria en acción transformadora. Documentación Social, 174, 95-116.

Da Ros, G. (2007). Economía solidaria: aspectos teóricos y experiencias. Unircoop. 5, (1), 9-27.

De Melo-Lisboa, A. (2004). Economia solidaria, economia barroca: a emergência da socioeconomia solidária na América Ibérica. https://bit.ly/3wLt6a5

Defourny, J., Favreau, L., y Laville, J. L. (1997). Inserción y nueva economía social: comparación internacional e invitación a la reflexión. Madrid: CIRIEC press.

Díaz-Foncea, M.; Bretos, I. y Marcuello, C. (2021): La experiencia de los Mercados Sociales en España. En Álvarez, J.F. y Marcuello, C. (coords.). Experiencias emergentes de la Economía Social en Iberoamérica. (2-28). Zaragoza, España: OIBESCOOP.

Diez, H. (2007) Economía solidaria, una riqueza invisible. Textos y reflexiones. México: Medellín, Cortesa Ediciones.

Etxezarreta, E., Etxezarreta, A., Zurbano, M., y Estensoro, M. (2015). Innovación social, políticas públicas y economía social y solidaria. REAS Euskadi, 5. https://bit.ly/2SGtB6E

Euskal Gizarte Ekonomia Sarea (EGES). https://bit.ly/3vFbXyD

França Filho, G. C. y Cunha, E. V. (2009). Incubação de redes de economia solidária. En A. D. Cattani, J. Laville e P. Hespanhao (coord), Dicionário Internacional da Outra economía. DOI. https://doi.org/10.1590/S198492302009000400007

García Jané, J. (2012). El Olmo de la Economía Solidaria. Mientrastanto 105. Disponible en http://www.mientrastanto.org/boletin-105/ensayo/el-olmo-dela-economia-solidaria.

- (2013). Economía solidaria: otra economía para otro desarrollo. Barcelona, Retos y Futuro del Desarrollo Económico Local press. https://bit.ly/3vFTTEy

- y Suriñach, R. (2019): Guia del Mercat Social. Serie Economia i Treball. 7. Barcelona: Diputació de Barcelona.

Godelier, M. (1998). El Enigma del Don, 1st ed. Buenos Aires, Editorial Paidos.

Guerra, P. (2004). Economía de la Solidaridad: Consolidación de un concepto a veinte años de sus primeras elaboraciones. Revista OIKOS, 1 (17), 1-11.

- (2005). Economía de la Solidaridad y Solidaridad en la Economía. Santiago, Chile, Univirtual press.

Jiménez, J. (2016). Movimiento de economía social y solidaria de ecuador. Circuitos económicos solidarios interculturales. Revista de la Academia, 21(1), 101-128.

Lopera, L. D., y Mora, S. B. (2009). Los circuitos económicos solidarios: Espacio de relaciones y consensos. Semestre Económico, 12 (25) 81-93.

Mance, E. (2002). Redes de colaboración solidaria. https://bit.ly/3p8r41h

- (2006). Cadenas productivas solidarias. Revista Vinculando. https://bit. ly/2SJm3Qy 
- (2008). La revolución de las redes: la colaboración solidaria como una alternativa post-capitalista a la globalización actual. México, Editorial Ítaca.

Melo-Lisboa, A. (2004). Mercado Solidário. En Cattani, A. (2004), La Otra Economia (pp. 293-305). Buenos Aires, Altamira press.

MESSE (Movimiento de Economía Social y Solidaria). https://bit.ly/34yS7cx

Moran-Esparza J.L. (2008). La economía social solidaria: Redes productivas. Contribuciones en la Economía, 1(1), 2-58.

Moulaert, F., y Ailenei, O. (2005): Social economy, third sector and solidarity relations: A conceptual synthesis from history to present. Urban Studies, 42(11): 2037-2053.

OLATUKOOP. https://bit.ly/3fA7fww

Pérez de Mendiguren, J. C., Etxezarreta, E., y Guridi, L. (2009). Economía Social, Empresa Social y Economía Solidaria: diferentes conceptos para un mismo debate. Papeles de Economía Solidaria, 1(1), 1-41.

Ramírez, A. (2017). Redes y circuitos económicos cooperativos para la innovación social y el desarrollo local: el caso de la Red Coopcentral en Colombia. Master's Thesis, Universidad Eafit Press.

Razeto, L. (1993). Los caminos de la economía de solidaridad. Santiago de Chile: Vivarium press.

- (1994): Fundamentos de una Teoría Económica Comprensiva. Santiago de Chile, Programa de Economía del Trabajo press.

- (1999). La economía de solidaridad: concepto, realidad y proyecto. Persona y sociedad, 13(2) https://bit.ly/2S2mkxU

Red de Economía Alternativa y Solidaria (REAS) (2011) Carta de Principios de Economía Solidaria. https://bit.ly/34zXubC

Red de Redes de economía alternativa y solidaria (REAS, 2019). Quienes somos. https://bit.ly/2R7eJ0G

Rodríguez Prieto, L. (2020): Apuntes de la Sesión 1 - Mercados Sociales: una realidad de transformación social. II Edición del Curso de Economía Social y Solidaria. IUDESCOOP-Universidad de Valencia.

Silva Urbina, G. (2013). Circuitos económicos solidarios y puesta en valor del patrimonio Working paper. https://bit.ly/2TrAYiF

Silva Rodríguez, P. A. (2017). Circuito turístico para diversificar la oferta del cantón Pallatanga provincia de Chimborazo. Bachelor's thesis, Universidad Nacional de Chimborazo.

Singer, P. (2002). A recente ressurreição da economia solidária no Brasil. Produzir para viver: os caminhos da produção não capitalista. Rio de Janeiro: Civilização Brasileira, 2.

Spear, R., Cornforth, C. y Aiken, M. (2009). The governance challenges of social enterprises: evidence from a UK empirical study. Annals of Public and Cooperative Economics, 80, 247-273.

Suriñach, R. (2017): Economias transformadoras en Barcelona, Barcelona, Marge Books. 
Tygel, D. (2010). Fluxos e informações na Economia Solidária: um novo olhar sobre as práticas. Cartilha Economia Solidária, 1. https://bit.ly/3c6UmYP

UNRISD-United Nations Research Institute for Social Development (2013). Potential and Limits of Social and Solidarity Economy. Event Brief. https://bit. ly/3g1xniS

Villalba-Eguiluz, U., y Pérez de Mendiguren, J. C. (2019). La economía social y solidaria como vía para el buen vivir. Revista Iberoamericana de Estudios de Desarrollo, 8 (1) 106-136.

Villalba-Eguiluz, U., Egia, A. y Pérez de Mendiguren, J. C. (2019): Sistemas Locales de Economía Social y Solidaria. Innovación, sostenibilidad, equidad e inclusión. UNFTSSE, UNRISD. Disponible en: https://knowledgehub.unsse. org/es/knowledge-hub/sistemas-locales-de-economia-social-y-solidaria-sless/

XES-Xarxa d'Economia Solidària de Catalunya (2019): Informe del Mercat Social 2019. Barcelona: Barcelona. https://bit.ly/2RZMTnp 